\title{
(E)-3-Furan-2-yl-N-p-tolyl-acrylamide and its Derivative DM489 Decrease Neuropathic Pain in Mice Predominantly by $\alpha 7$ Nicotinic Acetylcholine Receptor Potentiation
}

Hugo R. Arias, * Carla Ghelardini, Elena Lucarini, Han-Shen Tae,* Arsalan Yousuf, Irina Marcovich, Dina Manetti, Maria Novella Romanelli, Ana Belén Elgoyhen, David J. Adams, and Lorenzo Di Cesare Mannelli

Cite This: ACS Chem. Neurosci. 2020, 11, 3603-3614

Read Online

ACCESS |

Llll Metrics \& More

回国 Article Recommendations

ABSTRACT: The main objective of this study was to determine whether (E)-3-furan-2-yl-N-p-tolyl-acrylamide (PAM-2) and its structural derivative DM489 produce anti-neuropathic pain activity using the streptozotocin (STZ)- and oxaliplatin-induced neuropathic pain animal models. To assess possible mechanisms of action, the pharmacological activity of these compounds was determined at $\alpha 7$ and $\alpha 9 \alpha 10$ nicotinic acetylcholine receptors (nAChRs) and $\mathrm{Ca}_{\mathrm{V}} 2.2$ channels expressed alone or coexpressed with $G$ protein-coupled $\mathrm{GABA}_{\mathrm{B}}$ receptors. The animal results indicated that a single dose of $3 \mathrm{mg} / \mathrm{kg}$ PAM- 2 or DM489 decreases STZ-induced neuropathic pain in mice, and chemotherapy-induced neuropathic pain is decreased by PAM-2 (3 mg/ $\mathrm{kg}$ ) and DM489 $(10 \mathrm{mg} / \mathrm{kg})$. The observed anti-neuropathic pain
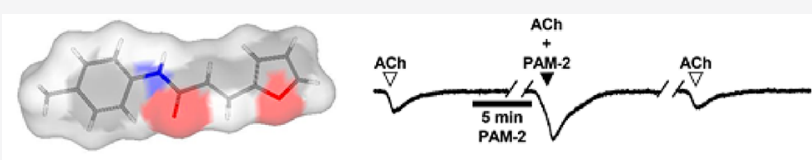

PAM-2

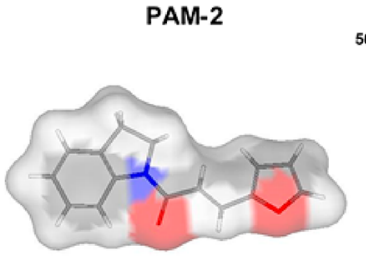

DM489 ${ }^{50 \mathrm{nA}} \frac{}{4 \mathrm{~s}}$

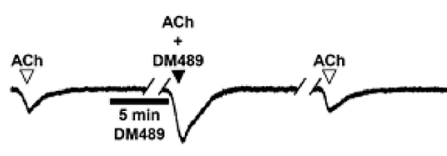
activity was inhibited by the $\alpha 7$-selective antagonist methyllycaco-

nitine. The coadministration of oxaliplatin with an inactive dose $(1 \mathrm{mg} / \mathrm{kg})$ of PAM-2 decreased the development of neuropathic pain after 14, but not 7, days of cotreatment. The electrophysiological results indicated that PAM-2 potentiates human (h) and rat (r) $\alpha 7 \mathrm{nAChRs}$ with 2-7 times higher potency than that for $\mathrm{hCa}_{\mathrm{V}} 2.2$ channel inhibition and an even greater difference compared to that for $\mathrm{r} \alpha 9 \alpha 10 \mathrm{nAChR}$ inhibition. These results support the notion that $\alpha 7 \mathrm{nAChR}$ potentiation is likely the predominant molecular mechanism underlying the observed anti-nociceptive pain activity of these compounds.

KEYWORDS: Neuropathic pain, positive allosteric modulators, nicotinic acetylcholine receptors, $C a_{V} 2.2$ channels

\section{INTRODUCTION}

Nicotinic acetylcholine receptors (nAChRs) such as the $\alpha 7$ and $\alpha 9 \alpha 10$ subtypes are members of the Cys-loop ligand-gated ion channel superfamily, which also comprises the $\gamma$-aminobutyric acid type $\mathrm{A}\left(\mathrm{GABA}_{\mathrm{A}}\right)$, glycine, and serotonin type 3 (5$\left.\mathrm{HT}_{3}\right)$ receptors. ${ }^{1}$ Both $\alpha 7$ and $\alpha 9 \alpha 10$ subtypes have been reported to be involved in pain-related processes, including neuropathic pain and chronic inflammation. $\alpha 9 \alpha 10$ nAChRs are expressed mainly in outer hair cells of the cochlea, ${ }^{2}$ endocrine cells, ${ }^{3}$ and various immune cells, ${ }^{4}$ and its inhibition decreases neuropathic pain in animal models. ${ }^{5,6}$ On the contrary, $\alpha 7 \mathrm{nAChRs}$ are abundantly expressed in the brain and peripheral tissues, including immunocompetent cells and nociceptive dorsal root ganglion (DRG) neurons, and different studies confirmed the role of this receptor subtype in inflammatory and neuropathic pain. ${ }^{6-9}$ Although the use of $\alpha 7$ knockout (KO) mice in principle supported the role of $\alpha 7$ $\mathrm{nAChRs}$ in pain processes, they are somehow controversial.
For instance, intraplantar injections of Complete Freund's Adjuvant, but not chronic constriction nerve injury, increased hyperalgesia and allodynia in $\alpha 7 \mathrm{KO}$ mice compared to wildtype mice, and the anti-nociceptive effects of systemic nicotine were observed only in wild-type animals. ${ }^{10}$ Although $\alpha 7 \mathrm{KO}$ mice did not show differences in thermal and mechanical hypersensitivity, they were less susceptible to the antinociceptive activity of choline (an agonist with relatively higher selectivity for $\alpha 7 \mathrm{nAChRs)}$ infusions compared to wildtype mice. ${ }^{11}$

Received: July 26, 2020

Accepted: October 5, 2020

Published: October 19, 2020 
Previous attempts to alleviate pathological conditions involving chronic pain were focused on selective $\alpha 7 \mathrm{nAChR}$ agonists. $^{8,12}$ However, their therapeutic efficacies have been limited due to potential side effects and increased receptor desensitization. Several laboratories have focused on the use of positive allosteric modulators (PAMs) with high selectivity for $\alpha 7$ nAChRs (e.g., PNU-120596 and PAM-2), which induce anti-nociceptive and anti-inflammatory effects in various animal models. ${ }^{6,13,14}$ In this regard, we compared the antineuropathic pain activity of PAM-2 [(E)-3-furan-2-yl- $N$ - $p$ tolyl-acrylamide $]^{15}$ with that of a novel structural derivative with relatively higher brain penetration, DM489 [(E)-3-(furan2-yl)-1-(indolin-1-yl)prop-2-en-1-one)] (see 3D structures in Figure 1), by using the oxaliplatin- and streptozotocin (STZ)induced neuropathic pain models. ${ }^{5,16-18}$

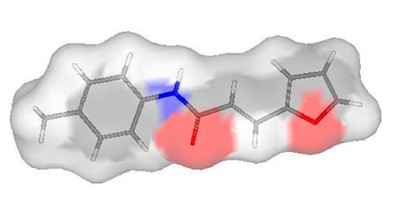

PAM-2

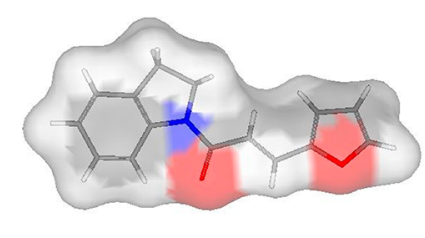

DM489
Figure 1. 3D molecular structure of PAM-2 [(E)-3-furan-2-yl- $N$ - $p$ tolyl-acrylamide] and DM489 [(E)-3-(furan-2-yl)-1-(indolin-1-yl)prop-2-en-1-one] with the van der Waals surface surrounding the molecule (stick model) and colored according to atom type: $\mathrm{O}$ (red), $\mathrm{N}$ (blue), $\mathrm{H}$ (white), and C (gray). Representations were generated using DSViewer Pro 6.0 (Accelrys, San Diego, CA).

To assess the molecular mechanisms underlying the observed anti-neuropathic pain activity of PAM-2 and DM489, their pharmacological activities were determined at $\alpha 7$ and $\alpha 9 \alpha 10$ nAChRs heterologously expressed in Xenopus laevis oocytes using the two-electrode voltage clamp recording technique. Given that voltage-gated N-type calcium $\left(\mathrm{Ca}_{\mathrm{V}} 2.2\right)$ channels modulated by $G$ protein-coupled GABA type $B$ receptors $\left(\mathrm{GABA}_{\mathrm{B}} \mathrm{Rs}\right)$ have been implicated in pain-related processes, ${ }^{5,19,20}$ the activity of PAM-2 and DM489 was also investigated on $\mathrm{Ca}_{\mathrm{V}} 2.2$ channels expressed alone or coexpressed with $\mathrm{GABA}_{\mathrm{B}} \mathrm{Rs}$ using the whole-cell patch clamp recording technique.

This study clearly demonstrated that both PAM-2 and DM489 induce anti-neuropathic pain activity in mice and that $\alpha 7 \mathrm{nAChR}$ potentiation, rather than $\alpha 9 \alpha 10 \mathrm{nAChR}$ and/or $\mathrm{Ca}_{\mathrm{V}} 2.2$ channel inhibition, is likely the predominant molecular mechanism underlying this activity. The results also suggested that PAM-2 and DM489 might be used for the prevention and treatment of (chronic) neuropathic pain, especially in chemotherapy and diabetes conditions.

\section{RESULTS AND DISCUSSION}

Chemical Synthesis. DM489 was synthesized by reacting (E)-3-(furan-2-yl)acrylic acid with indoline, using $\mathrm{N}$-(3dimethylaminopropyl)- $N^{\prime}$-ethylcarbodiimide (EDC) and 1hydroxybenzotriazole hydrate $(\mathrm{HOBt})$ as coupling reagents (Scheme 1). For convenience, the same method was also applied to the preparation of PAM-2, using $p$-toluidine as a reactant. This procedure gave high yields for both compounds and better purity ( $>99.5 \%$ for PAM-2 and $>95 \%$ for DM489) than those obtained by previous methods. ${ }^{15}$
Scheme 1. Chemical Synthesis of PAM-2 [(E)-3-Furan-2-yl$N$-p-tolyl-acrylamide $]$ and DM489 [(E)-3-(Furan-2-yl)-1(indolin-1-yl)prop-2-en-1-one $]^{a}$

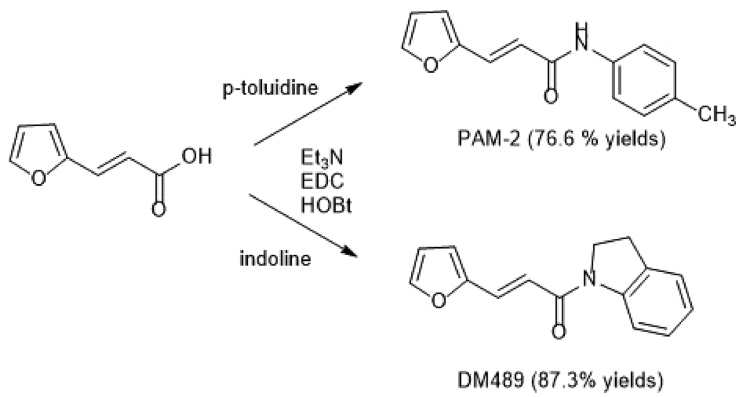

${ }^{a} \mathrm{Et}_{3} \mathrm{~N}$, triethylamine; EDC, $N$-(3-dimethylaminopropyl)- $N^{\prime}$-ethylcarbodiimide; HOBt, 1-hydroxybenzotriazole hydrate.

Brain Permeability Prediction for PAM-2 and DM489. To predict whether PAM-2 and DM489 can penetrate the brain, their lipophilicity $(\log \mathrm{P})$ and blood-brain barrier penetration $(\operatorname{LogBB})$ values were calculated (Table 1$)$. The

Table 1. Lipophilicity (LogP) and Blood-Brain Barrier Permeability (LogBB) of PAM-2 and DM489

$\begin{array}{ccc}\text { compound } & \log \mathrm{P} & \operatorname{LogBB} \\ \text { PAM-2 } & 2.96 & 0.09 \\ \text { DM489 } & 2.76 & 0.17\end{array}$

results indicated that, although both compounds have similar lipophilicity $(\log P>2)$, DM489 has a relatively higher brain permeability (0.17) than that of PAM-2 (0.09). This is a consequence of the higher polarity of the secondary amine of PAM-2, which has a H-bond donor, whereas DM489 is a tertiary amine with no $\mathrm{H}$-bond donor (see Figure 1). Previous in vivo animal studies showed that intraperitoneal (ip) injections of PAM-2 induced several behavioral effects in mice, ${ }^{21-23}$ thus suggesting an active brain permeability of PAM-2.

PAM-2 or DM489 Decreased Drug-Induced Neuropathic Pain in Mice. The pain-relieving properties of PAM-2 and DM489 were evaluated using different animal models of neuropathic pain. In Figure 2, the effects of these PAMs against streptozotocin (STZ)-induced diabetic neuropathic pain are shown. STZ-induced hypersensitivity to cold noxious stimuli (i.e., allodynia-like measurements using the cold plate test) was developed, where STZ decreased the pain threshold (i.e., increased pain sensitivity) to $9.8 \pm 0.4 \mathrm{~s}$ in comparison to those of vehicle-treated animals $(18.5 \pm 0.2 \mathrm{~s}, n=10)$ (oneway ANOVA; $P<0.01$ ). Interestingly, the treatment with 3 $\mathrm{mg} / \mathrm{kg}$, but not $1 \mathrm{mg} / \mathrm{kg}$ PAM-2, was able to significantly $(P<$ 0.05 ) decrease neuropathic pain between 15 and $45 \mathrm{~min}$, with complete reversal at $30 \mathrm{~min}$. On the contrary, DM489 was active at $3(P<0.05)$ and $10(P<0.01) \mathrm{mg} / \mathrm{kg}$ compared to vehicle-treated animals. No statistical differences were observed between $3 \mathrm{mg} / \mathrm{kg}$ PAM-2 and DM489 $(P>0.05)$.

To study the drug's profile against a different model of chronic pain, neuropathic conditions were evoked using the neurotoxic anti-cancer agent oxaliplatin., ${ }^{5,16}$ Treatment (ip) with $2.4 \mathrm{mg} / \mathrm{kg}$ oxaliplatin progressively developed neuropathic pain in mice as evaluated by the cold plate test. The licking latency decreased to $9.5 \pm 0.2 \mathrm{~s}$ in comparison to in vehicle-treated animals $(18.7 \pm 0.2$ s, $n=10)(P<0.01)$ 


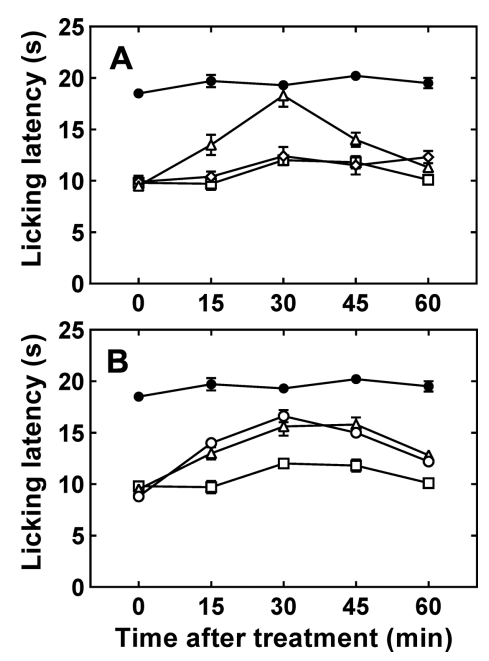

Figure 2. Effect of (A) PAM-2 and (B) DM489 on streptozotocin (STZ)-induced neuropathic pain in mice. Mice $(n=10 /$ condition) were treated with a single injection (ip) of $100 \mathrm{mg} / \mathrm{kgSTZ}(\square)$ to develop neuropathic pain. On day 15, (A) PAM-2 [1 $(\diamond)$ and $3 \mathrm{mg} /$ $\mathrm{kg}(\Delta)]$ or $(\mathrm{B}) \mathrm{DM} 489[3(\Delta)$ and $10(\mathrm{O}) \mathrm{mg} / \mathrm{kg}]$ was administered per os (p.o.), and the response to a thermal stimulus was subsequently evaluated by the cold plate test. The licking latency (mean \pm SEM in seconds) for the first signs of pain-related behavior was recorded before and 15, 30, 45, and 60 min after treatment. Bonferroni post hoc analyses indicated that STZ + vehicle $(\square)$ induced neuropathic pain during the whole testing time (i.e., $0-60 \mathrm{~min})[P<0.01$ vs vehicle + vehicle-treated mice $(\bullet)]$ and that $3 \mathrm{mg} / \mathrm{kg}$ PAM- $2(\Delta)$ decreased drug-induced neuropathic pain at $15(P<0.05)$ and $30(P<0.01)$ min period $(A)$, whereas $3(\Delta)$ and $10(O) \mathrm{mg} / \mathrm{kg}$ DM489 decreased neuropathic pain during the $15-30$ and $15-45$ min periods $(P<$ $0.01)$, respectively, compared to that for $S T Z+$ vehicle $(\square)$.

(Figure 3). The effect elicited by a single p.o. administration of PAM-2 (Figure 3A) or DM489 (Figure 3B) was subsequently evaluated on day 15 . Bonferroni post hoc analyses indicated that a dose of $3 \mathrm{mg} / \mathrm{kg}(P<0.01)$, but not $1 \mathrm{mg} / \mathrm{kg}$, PAM-2 induced pain relief, starting $15 \mathrm{~min}$ after treatment and lasting for $45 \mathrm{~min}$. In addition, DM489 produced pain relief at doses of 10 and $30 \mathrm{mg} / \mathrm{kg}(P<0.01)$, and the effect was quicker (peak at $15 \mathrm{~min}$ ) than that for PAM-2 (peak at $30 \mathrm{~min}$ ). These results indicated that both compounds at different doses are capable of inducing anti-nociceptive effects but that the onset of PAM-2's action is double that of DM489.

Anti-Neuropathic Pain Activity of PAM-2 and DM489 is Mediated by $\boldsymbol{\alpha} 7$-Containing nAChRs. To determine whether the anti-neuropathic pain activity of PAM-2 and DM489 was mediated by $\alpha 7$-containing nAChRs, the effect of $6 \mathrm{mg} / \mathrm{kg}$ methyllycaconitine citrate (MLA), an $\alpha 7$-selective antagonist, ${ }^{24}$ was determined on mice treated with an active dose of PAM-2 (3 mg/kg) (Figure 4A) or DM489 $(30 \mathrm{mg} / \mathrm{kg}$ ) (Figure 4B). Statistical analyses of the results indicated that the anti-neuropathic pain effect elicited by PAM-2 and DM489 was completely blocked by MLA $(P<0.01)$, whereas MLA did not change per se the neuropathic pain effect elicited by oxaliplatin.

PAM-2 Decreased the Development of OxaliplatinInduced Neuropathic Pain. To determine whether PAM-2 decreases the development of oxaliplatin-induced neuropathic pain, an inactive dose of PAM-2 $(1 \mathrm{mg} / \mathrm{kg})$ was coadministered with $2.4 \mathrm{mg} / \mathrm{kg}$ oxaliplatin using the same protocol as for oxaliplatin alone, and cold plate tests were performed on day 15. Bonferroni post hoc analyses indicated that PAM-2 +
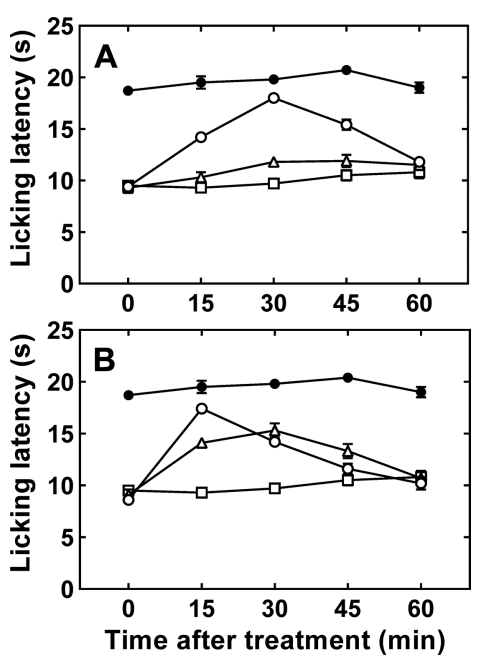

Figure 3. Effect of (A) PAM-2 and (B) DM489 on oxaliplatininduced neuropathic pain in mice. Mice $(n=10 /$ condition $)$ were treated (ip) with $2.4 \mathrm{mg} / \mathrm{kg}$ oxaliplatin to induce neuropathic pain. On day 15, (A) PAM-2 [1 ( $\Delta)$ and $3 \mathrm{mg} / \mathrm{kg}(\mathrm{O})]$ or (B) DM489 [10 $(\Delta)$ and $30(\bigcirc) \mathrm{mg} / \mathrm{kg}]$ was administered (p.o.), and the response to a thermal stimulus was subsequently evaluated by the cold plate test. The licking latency (mean \pm SEM) for the first signs of pain-related behavior was recorded before and 15, 30, 45, and $60 \mathrm{~min}$ after treatment. Bonferroni post hoc analyses indicated that oxaliplatin + vehicle induced neuropathic pain $(\square)$ during the whole testing time $[P<0.01$ vs vehicle + vehicle-treated mice $(\bullet)]$ and that $3(O)(P<$ $0.01)$, but not $1 \mathrm{mg} / \mathrm{kg}(\Delta)(P>0.05)$, PAM-2 decreased druginduced neuropathic pain during the $15-45 \mathrm{~min}$ period $(\mathrm{A})$, whereas $10 \mathrm{mg} / \mathrm{kg}$ DM489 decreased neuropathic pain during the 15-30 min period $(\Delta)$ and $30 \mathrm{mg} / \mathrm{kg}$ DM489 decreased neuropathic pain during the 15-45 min period $(O)(P<0.01$ for both) $(\mathrm{B})$, compared to oxaliplatin + vehicle-treated mice $(\square)$.

oxaliplatin-treated animals have a significantly higher pain threshold compared to oxaliplatin-treated animals after 14, but not 7 , days of treatment $(P<0.01)$ (Figure 5A). Interestingly, an additional administration of PAM-2 $30 \mathrm{~min}$ after the described cotreatment, produced a higher pain reversion in the 0-30 min time regime compared to the same period in the previous cotreatment $(P<0.01$; Figure $5 B)$.

The animal results indicated that that a single dose of either $3 \mathrm{mg} / \mathrm{kg}$ PAM-2 or DM489 was able to decrease STZ-induced diabetic neuropathic pain. In addition, PAM-2 decreased oxaliplatin-induced neuropathic pain at a lower dose $(3 \mathrm{mg} /$ $\mathrm{kg})$ than that used with DM489 $(10 \mathrm{mg} / \mathrm{kg})$; however, the latter produced a faster onset of action than that for PAM-2. Since electrophysiology results showed that DM489 and PAM2 enhance ACh-evoked $\mathrm{r} \alpha 7$ activity with similar potency and efficacy, a possible explanation for the anti-nociceptive differences observed between these compounds might be based on the inhibitory component observed for DM489, but not for PAM-2, and/or distinct outcomes between druginduced neuropathic models (i.e., chemotherapy-induced neuropathy is in general more painful than that elicited by diabetic drugs). In addition, the faster onset observed for DM489 compared to PAM-2 could be due to the relatively greater ability of the former drug to cross the blood-brain barrier.

Additional animal experiments also showed that PAM-2 can decrease the development of oxaliplatin-induced neuropathic pain in mice, which could be of clinical relevance in the prevention of chemotherapy-induced chronic pain in cancer 

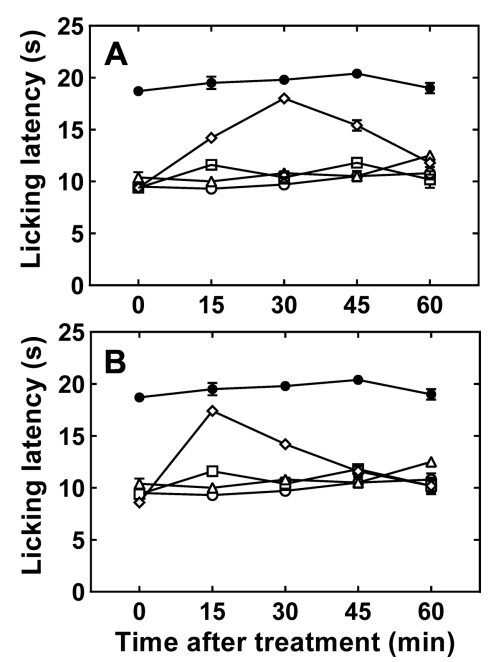

Figure 4. Effect of methyllycaconitine (MLA) on the anti-neuropathic pain activity elicited by (A) PAM-2 and (B) DM489. Mice $(n=10 /$ condition) were treated (ip) with $2.4 \mathrm{mg} / \mathrm{kg}$ oxaliplatin to develop neuropathic pain. On day $15,6 \mathrm{mg} / \mathrm{kg}$ MLA was administered (ip) 15 min before (A) $3 \mathrm{mg} / \mathrm{kg}$ PAM-2 (p.o.) ( $\square$ ) or (B) $30 \mathrm{mg} / \mathrm{kg}$ DM 489 $(\square)$. The response of MLA to the respective effect elicited by (A) PAM-2 ( $\square$ )and (B) DM489 ( $\square$ ) was subsequently compared to that for PAM-2 $(\diamond)$ and DM489 $(\diamond)$ by the cold plate test. The licking latency (mean \pm SEM) for the first signs of pain-related behavior was recorded before and $15,30,45$, and $60 \mathrm{~min}$ after treatment. Bonferroni post hoc analysis indicated that MLA inhibited the antineuropathic pain effect elicited by PAM-2 during the 15-45 min period $(\square)$ and by DM489 during the $15-30$ min period $(\square)(P<$ 0.01 for both), compared to the respective drug + vehicle-treated animals $(\diamond)$, whereas MLA + oxaliplatin-treated animals $(\Delta)$ were not different from oxaliplatin + vehicle treated animals $(P>0.05)(O)$.

patients, especially considering that PAM-2 has a higher efficacy than that of DM489. Our study based on drug-induced neuropathic pain models and especially the chemotherapybased model, which mainly induces neuropathy toxicity without an inflammatory component, expanded previous results showing that PAM-2 reduces neuropathic pain induced by sciatic nerve ligation, ${ }^{25}$ which has a strong inflammatory component. ${ }^{16}$

PAM-2 and DM489 Potentiated ACh-Activated $\alpha 7$ nAChRs in a Concentration-Dependent Manner. The activity of PAM-2 and DM489 was determined at human and rat $\alpha 7$ nAChRs (>90\% amino acid sequence homology) heterologously expressed in X. laevis oocytes using the twoelectrode voltage clamp recording technique. At $10 \mu \mathrm{M}$, PAM2 and DM489 potentiated ACh-evoked h $\alpha 7$ currents by $30 \pm$ $4 \%$ and $27 \pm 6 \%(n=5-6)$, respectively, in a reversible manner, indicating that receptors are not continuously stimulated upon washout (Figure 6A). Similarly, $10 \mu \mathrm{M}$ PAM-2 and DM489 potentiated $\mathrm{r} \alpha 7$ nAChR-mediated currents by $15 \pm 4 \%$ and $30 \pm 8 \%(n=5-8)$, respectively (Figure 7A).

The concentration-response relationships for PAM-2 and DM489, relative to that induced by $\mathrm{ACh}$ at $20 \%$ maximal effective concentrations $\left(\mathrm{EC}_{20}\right)$ [i.e., $30 \mu \mathrm{M}$ for $\mathrm{h} \alpha 7$, and 160 $\mu \mathrm{M}$ for $\mathrm{r} \alpha 7$ (see Figure 7B)], indicated that both compounds enhanced ACh-evoked currents at $\mathrm{h} \alpha 7$ (Figure 6B) and $\mathrm{r} \alpha 7$ (Figure 7C) nAChRs with comparable potencies (Table 2). Although both PAM-2 and DM489 enhanced r $\alpha 7$ nAChRs with 3- to 4-fold higher potency than that at h $\alpha 7 \mathrm{nAChRs,}$ their efficacies (i.e., $\Delta E_{\max }$ ) were higher at h $\alpha 7 \mathrm{nAChRs}$
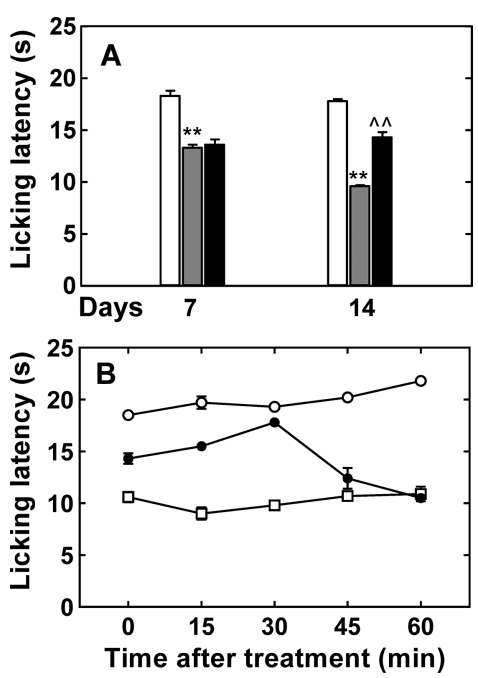

Figure 5. PAM-2 decreased the development of oxaliplatin-induced neuropathic pain. Mice ( $n=10 /$ condition) were treated (ip) with 2.4 $\mathrm{mg} / \mathrm{kgoxaliplatin}$ alone (gray) or coadministered with an inactive dose ( $1 \mathrm{mg} / \mathrm{kg}$; p.o.) of PAM-2 (black). (A) Effect of PAM-2 after 7 and 14 days of cotreatment with oxaliplatin. Cold plate tests were determined $24 \mathrm{~h}$ after the last administration and the pain threshold values (mean \pm SEM) compared between drug- and vehicle-treated animals (white). Bonferroni post hoc analyses indicated that oxaliplatin + vehicle induced neuropathic pain after 7 and 14 days of treatment $[* * P<0.01$ vs vehicle + vehicle-treated mice (white)], and that PAM$2+$ oxaliplatin decreased neuropathic pain after 14, but not 7, days of treatment $\hat{[} P<0.01$ vs oxaliplatin + vehicle-treated mice (gray) $]$. (B) Thirty minutes after an additional administration of $1 \mathrm{mg} / \mathrm{kg}$ PAM-2, the pain threshold (mean \pm SEM) was recorded at $0,15,30,45$, and $60 \mathrm{~min}$. Bonferroni post hoc analyses indicated that oxaliplatin + vehicle-treated mice developed neuropathic pain during the whole testing time $(\square)[P<0.01$ vs vehicle + vehicle-treated mice $(O)]$, and that PAM-2 decreased neuropathic pain $(\bullet)$ during the 0-30 min period $(P<0.01$ vs oxaliplatin + vehicle-treated mice $)$.

(120\%-150\%) compared to that at $\mathrm{r} \alpha 7 \mathrm{nAChRs}(\sim 30 \%)$ (Table 2). The calculated $n_{\mathrm{H}}$ values (i.e., $n_{\mathrm{H}}>1.5$ ) (Table 2) support a cooperative mechanism at both $\mathrm{h} \alpha 7$ and $\mathrm{r} \alpha 7$ nAChRs.

By using the two-component Hill equation [see eq.] 1], we were able to discriminate the potentiating and inhibitory effects of both PAM- 2 and DM489 at $\alpha 7$ nAChRs. The results indicated that concentrations above $100 \mu \mathrm{M}$ PAM-2 and 30 $\mu \mathrm{M}$ DM489 started to inhibit, probably by a negative allosteric modulatory mechanism at $\mathrm{r} \alpha 7$ (Figure $7 \mathrm{C}$ ), but not h $\alpha 7$ (Figure 6B), nAChRs. Comparison of the half-maximal effective and inhibitory concentrations $\left(\mathrm{EC}_{50}\right.$ and $\mathrm{IC}_{50}$, respectively) (Table 2) showed that PAM-2 potentiated $\mathrm{r} \alpha 7$ nAChRs with $>8$-fold higher potency than that elicited by inhibition ( 12 vs $>100 \mu \mathrm{M}$ ), whereas DM489 potentiated the $\mathrm{r} \alpha 7 \mathrm{nAChR}$ with $\sim 6$-fold higher potency than that elicited by inhibition (9 vs $56 \mu \mathrm{M}$ ).

PAM-2 and DM489 Inhibited $r \alpha 9 \alpha 10$ nAChRs with Different Potencies and in a Voltage-Independent Manner. To determine the inhibitory activity of PAM-2 and DM489 at $\mathrm{r} \alpha 9 \alpha 10 \mathrm{nAChRs,} \mathrm{two-electrode} \mathrm{voltage} \mathrm{clamp}$ experiments were performed on nAChRs expressed in Xenopus oocytes. Both compounds inhibit ACh $(10 \mu \mathrm{M})$-evoked currents in a concentration-dependent manner (Figure $8 \mathrm{~A}$ ), and the concentration-response analyses (Figure 8B) showed that the inhibitory potency for DM489 was 4-fold higher than 
A
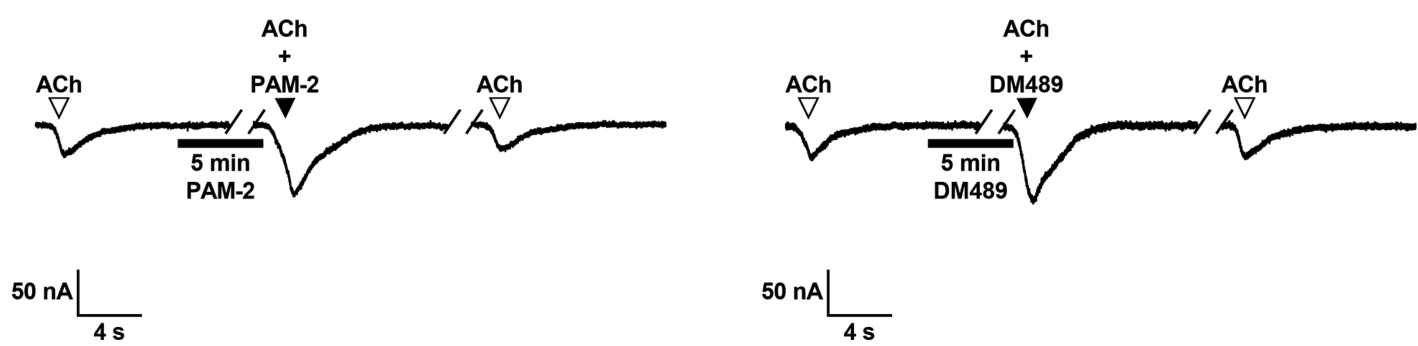

\section{B}

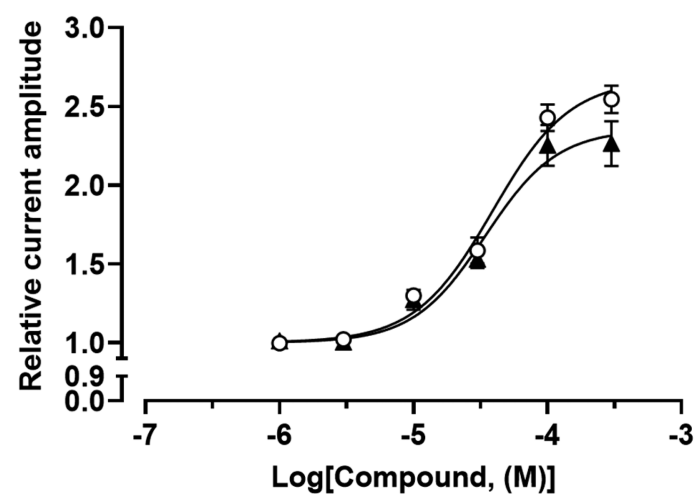

Figure 6. Effect of PAM- 2 and DM489 at ACh-activated h $\alpha 7 \mathrm{nAChRs} \mathrm{expressed} \mathrm{in} \mathrm{Xenopus} \mathrm{oocytes.} \mathrm{(A)} \mathrm{Representative} \mathrm{ACh} \mathrm{(30} \mu \mathrm{M})$-evoked h $\alpha 7$ currents obtained at $-80 \mathrm{mV}$ in the absence and presence of $10 \mu \mathrm{M}$ PAM-2 or DM489 and after washout. $\nabla$, ACh alone; $\nabla$, coapplication of ACh + compound after $5 \mathrm{~min}$ incubation (-) with compound alone; $\nabla$, ACh alone after washout. (B) Concentration-response relationships obtained for PAM-2 (O) and DM489 ( $(\boldsymbol{\Delta})$-induced potentiation of ACh-evoked current amplitude at $\mathrm{h} \alpha 7 \mathrm{nAChRs}$. Current amplitudes (mean \pm SEM; $n=$ 5-6) were normalized to the response elicited by $30 \mu \mathrm{M}$ ACh alone (corresponding to its $\mathrm{EC}_{20}$ at $\mathrm{h} \alpha 7 \mathrm{nAChRs).} \mathrm{The} \mathrm{calculated} \mathrm{potentiating} \mathrm{EC}_{50}$, $\Delta E_{\max }$, and $n_{\mathrm{H}}$ values are summarized in Table 2.

that for PAM-2 (Table 2). Given that the observed $n_{\mathrm{H}}$ values were close to 2 (Table 2 ) indicated that the inhibitory process is mediated by a cooperative mechanism.

Moreover, the voltage-dependence of $\mathrm{r} \alpha 9 \alpha 10$ inhibition, as shown in the representative current-voltage $(I-V)$ curves (Figure 8C), indicated that DM489 inhibition was voltageindependent. Specifically, responses were equally inhibited (Paired Student's $t$ test; $P=0.38)$ by both negative $(-90 \mathrm{mV})$ hyperpolarized potentials ( $\left.\% I / I_{\max }=63 \pm 8 \%, n=6\right)$ and positive $(+40 \mathrm{mV})$ depolarized potentials $(57 \pm 6 \%, n=6)$ (Figure $8 \mathrm{C}$ ), suggesting that the inhibition is voltageindependent. Although this result supports a competitive inhibitory mechanism, we cannot rule out the possibility of channel pore blockade at higher concentrations. Since PAM-2 was $>7$-fold more potent enhancing $r \alpha 7$ than inhibiting r $\alpha 9 \alpha 10$ nAChRs, it is unlikely that the latter subtype is involved in the anti-neuropathic pain activity elicited by these compounds.

PAM-2 and DM489 Inhibited Ca 2.2 Channels Alone but Not Those Coupled to $\mathrm{GABA}_{\mathrm{B}}$ Rs. A class of $\alpha$ conotoxins that exhibit potent anti-nociceptive activity have been shown to not only inhibit $\alpha 9 \alpha 10 \mathrm{nAChRs}$ but also $\mathrm{Ca}_{\mathrm{V}} 2.2$ channels via $\mathrm{G}$ protein-coupled $\mathrm{GABA}_{\mathrm{B}}$ receptor activation. $^{19,26}$ Given that neither PAM-2 nor DM489 have been tested on either $\mathrm{GABA}_{\mathrm{B}} \mathrm{Rs}$ or $\mathrm{Ca}_{\mathrm{V}} 2.2$ channels, we investigated the activity of these compounds on HEK293T cells expressing $\mathrm{hCa}_{\mathrm{V}} 2.2$ channels alone or coexpressing $\mathrm{GABA}_{\mathrm{B}} \mathrm{Rs}$ and $\mathrm{Ca}_{\mathrm{V}} 2.2$, respectively.
Depolarization-activated $\mathrm{Ba}^{2+}$ currents $\left(I_{\mathrm{Ba}}\right)$ recorded from HEK293T cells transiently cotransfected with $\mathrm{GABA}_{B} \mathrm{R}$ and $\mathrm{hCa}_{\mathrm{V}} 2.2$ channels were reversibly inhibited by PAM- 2 and DM489 but were not antagonized by $1 \mu \mathrm{M}$ CGP55845, a selective $\mathrm{GABA}_{\mathrm{B}} \mathrm{R}$ antagonist. In contrast, the inhibition of $I_{\mathrm{Ba}}$ by $50 \mu \mathrm{M}$ baclofen, a $\mathrm{GABA}_{\mathrm{B}} \mathrm{R}$ agonist, was antagonized by CGP55845 (Figure 9A). However, in HEK293T cells expressing $\mathrm{hCa}_{\mathrm{V}} 2.2$ alone, both PAM-2 (Figure 9B) and DM489 (Figure 9C) inhibited whole-cell $I_{\mathrm{Ba}}$ values in a concentration-dependent manner, and the calculated $\mathrm{IC}_{50}$ values were $89 \pm 15$ and $122 \pm 25 \mu \mathrm{M}(n=4)$, respectively (Table 2). These results demonstrated that both PAM-2 and DM489 inhibit $\mathrm{hCa}_{\mathrm{V}} 2.2$ channels directly without involving the $\mathrm{G}$ protein-coupled $\mathrm{GABA}_{\mathrm{B}} \mathrm{R}$. Thus, these compounds must have a mechanism distinct to that of analgesic $\alpha$-conotoxins (e.g., Vcl.1 and $\mathrm{Rg} 1 \mathrm{~A}$ ), which inhibit $\mathrm{GABA}_{\mathrm{B}} \mathrm{R}$ coupled $\mathrm{Ca}_{\mathrm{V}} 2.2$ channels. $^{19}$ PAM-2 and DM489 appear to act similar to coronaridine congeners, which also exhibit anti-neuropathic pain activity and inhibit $\mathrm{Ca}_{\mathrm{V}} 2.2$ channels directly. ${ }^{5}$

Previous studies clearly identified $\mathrm{Ca}_{\mathrm{V}} 2.2$ channels in painrelated mechanisms and as targets for the anti-nociceptive activity of a variety of selective inhibitors. ${ }^{5,19,20,27}$ Moreover, both $\mathrm{Ca}_{\mathrm{V}} 2.2$ channels and $\alpha 7 \mathrm{nAChRs}$ are expressed in DRG neurons, where they modulate the release of glutamate onto dorsal horn neurons, enhancing excitatory signaling in these neurons. ${ }^{6,9}$ Although this overlapping expression opens the possibility for complementary mechanisms, our study demonstrated that PAM-2 and DM489 inhibit $\mathrm{Ca}_{\mathrm{V}} 2.2$ channels with 
A
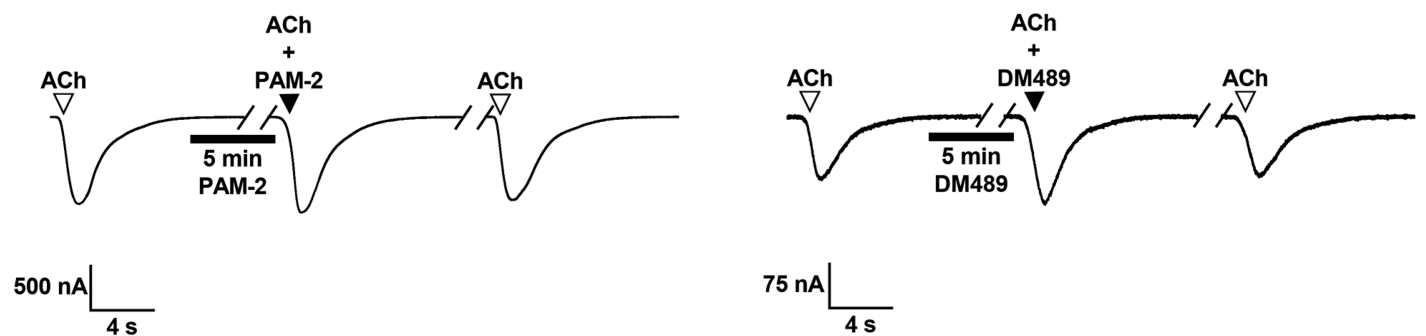

B

C
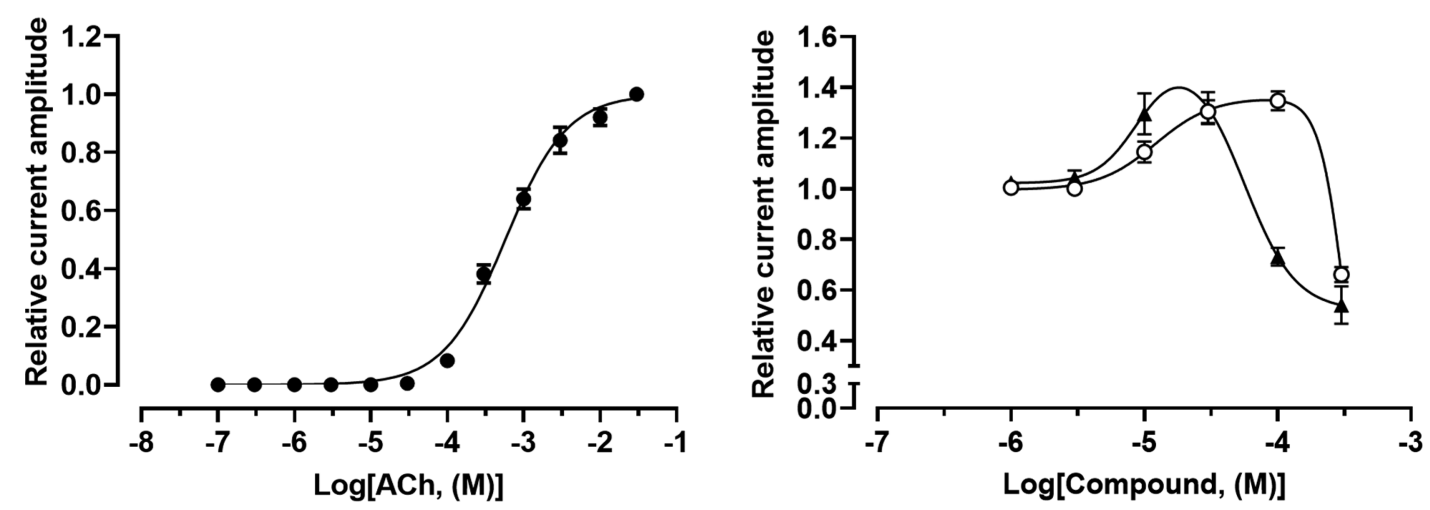

Figure 7. Effect of PAM-2 and DM489 on ACh-activated $\mathrm{r} \alpha 7$ nAChRs expressed in Xenopus oocytes. (A) Representative ACh (160 $\mu$ M)-evoked $\mathrm{r} \alpha 7$ currents obtained at $-80 \mathrm{mV}$ in the absence and presence of $10 \mu \mathrm{M}$ PAM-2 or DM489 and after compound washout. $\nabla$, ACh alone; $\nabla$, coapplication of $\mathrm{ACh}+$ compound after $5 \mathrm{~min}$ incubation (-) with compound alone; $\nabla$, ACh alone after washout. (B) Concentration-response relationships for ACh-evoked current amplitudes at $\mathrm{r} \alpha 7 \mathrm{nAChRs}$. Current amplitudes (mean $\pm \mathrm{SEM} ; n=5$ ) were normalized to the response elicited by $30 \mathrm{mM}$ ACh, and an $\mathrm{ACh} \mathrm{EC}_{50}$ value of $575 \pm 32 \mu \mathrm{M}$ was calculated. (C) Concentration-response relationships obtained for PAM-2 (O) and DM489 ( $\mathbf{\Delta}$ )-induced potentiation of ACh-evoked current amplitude at r $\alpha 7$ nAChRs. Current amplitudes (mean \pm SEM; $n=5-8$ ) were normalized to the response elicited by $160 \mu \mathrm{M}$ ACh alone [corresponding to its $\mathrm{EC}_{20}$ at $\mathrm{r} \alpha 7 \mathrm{nAChRs}$; see (B)]. The calculated $\mathrm{EC}_{50}, \Delta E_{\max } \mathrm{IC}_{50}$, and $n_{\mathrm{H}}$ values are summarized in Table 2 .

Table 2. Pharmacological Activity of PAM-2 and DM489 at $\alpha 7$ and $\alpha 9 \alpha 10$ nAChR Subtypes and Ca 2.2 Channels

\begin{tabular}{|c|c|c|c|c|c|c|}
\hline \multirow[b]{2}{*}{ molecular target } & \multirow[b]{2}{*}{ compound } & \multicolumn{3}{|c|}{ potentiation } & \multicolumn{2}{|c|}{ inhibition } \\
\hline & & $\mathrm{EC}_{50}(\mu \mathrm{M})$ & $n_{\mathrm{H}}$ & $\Delta E_{\max }(\%$ control $)$ & $\mathrm{IC}_{50}(\mu \mathrm{M})$ & $n_{\mathrm{H}}$ \\
\hline \multirow[t]{2}{*}{$\mathrm{h} \alpha 7^{a}$} & PAM-2 & $39 \pm 6$ & $1.50 \pm 0.26$ & $155 \pm 9$ & no activity & \\
\hline & DM489 & $34 \pm 7$ & $1.62 \pm 0.45$ & $126 \pm 14$ & no activity & \\
\hline \multirow[t]{2}{*}{$\mathrm{r} \alpha 7^{b}$} & PAM-2 & $12 \pm 3$ & $2.28 \pm 1.41$ & $35 \pm 4$ & $>100^{e}$ & \\
\hline & DM489 & $9 \pm 3$ & $2.81 \pm 3.47$ & $32 \pm 6$ & $56 \pm 14^{e}$ & $2.25 \pm 0.60^{e}$ \\
\hline \multirow[t]{2}{*}{$\mathrm{r} \alpha 9 \alpha 10^{c}$} & PAM-2 & no activity & & & $174 \pm 18$ & $2.17 \pm 0.30$ \\
\hline & DM489 & no activity & & & $39 \pm 2$ & $2.41 \pm 0.27$ \\
\hline \multirow[t]{2}{*}{$h C a_{\mathrm{V}} 2.2^{d}$} & PAM-2 & no activity & & & $89 \pm 15$ & $1.2 \pm 0.2$ \\
\hline & DM489 & no activity & & & $122 \pm 25$ & $1.0 \pm 0.1$ \\
\hline
\end{tabular}

${ }^{a}$ Values were calculated from Figure $6 \mathrm{~B} .{ }^{b}$ Values were calculated from Figure $7 \mathrm{C}$. ${ }^{c}$ Values were obtained from Figure $8 \mathrm{~B} .{ }^{d}$ Values were obtained from Figure 9C. ${ }^{e}$ Values obtained by using two-component Hill eq 1.

potencies relatively lower than that determined for $\alpha 7 \mathrm{nAChR}$ potentiation (see Table 2), suggesting that the latter is the predominant mechanism underlying the observed anti-neuropathic activity in mice.

The widespread expression of $\alpha 7 \mathrm{nAChRs}$ in neurons, microglia, astrocytes, and lymphocytes suggests their preeminent role in neuro-immune crosstalk. ${ }^{7}$ Accordingly, a protective $\alpha 7$-mediated microglial function has been detected in hippocampal cultures under brain ischemic conditions. ${ }^{28}$ Studies showing that $\mathrm{nAChR}$ ligands lose anti-nociceptive activity when $\alpha 7 \mathrm{KO}$ mice are used ${ }^{10,11}$ support the concept that alterations in peripheral and central mechanisms involving $\alpha 7 \mathrm{nAChRs}$ could be also involved in neuropathic pain. In particular, $\alpha 7$-selective agonists produced neuroprotective effects by preventing oxaliplatin-induced damages in peripheral nerves and DRG neurons, ${ }^{8,12}$ suggesting that $\alpha 7$ nAChRs expressed in DRG neurons are involved in nociception mechanisms. ${ }^{9}$ Moreover, oxaliplatin treatment induced $\alpha 7$ $\mathrm{nAChR}$ downregulation in the peripheral and central nervous systems, whereas the repeated treatment with selective agonists 
A
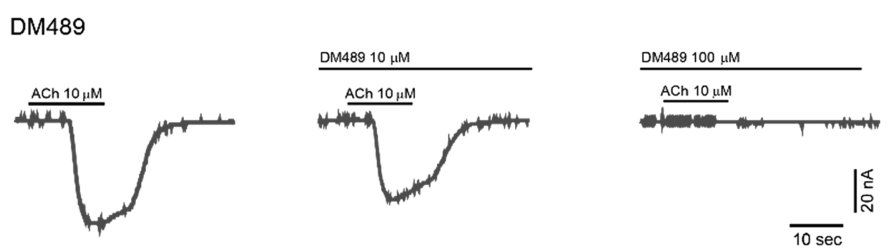

PAM-2

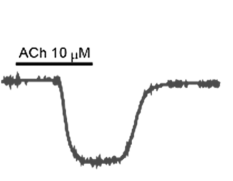

PAM-2 $100 \mu \mathrm{M}$
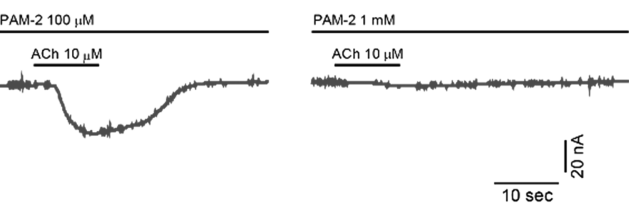

B

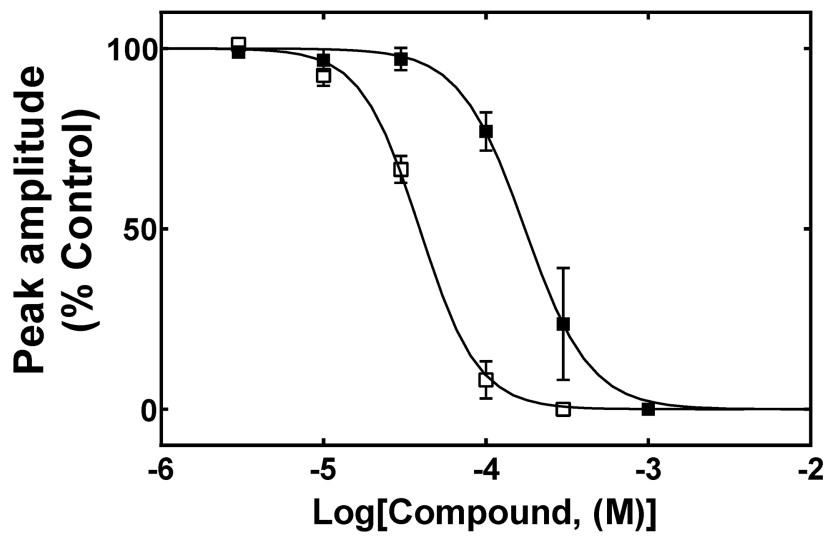

C
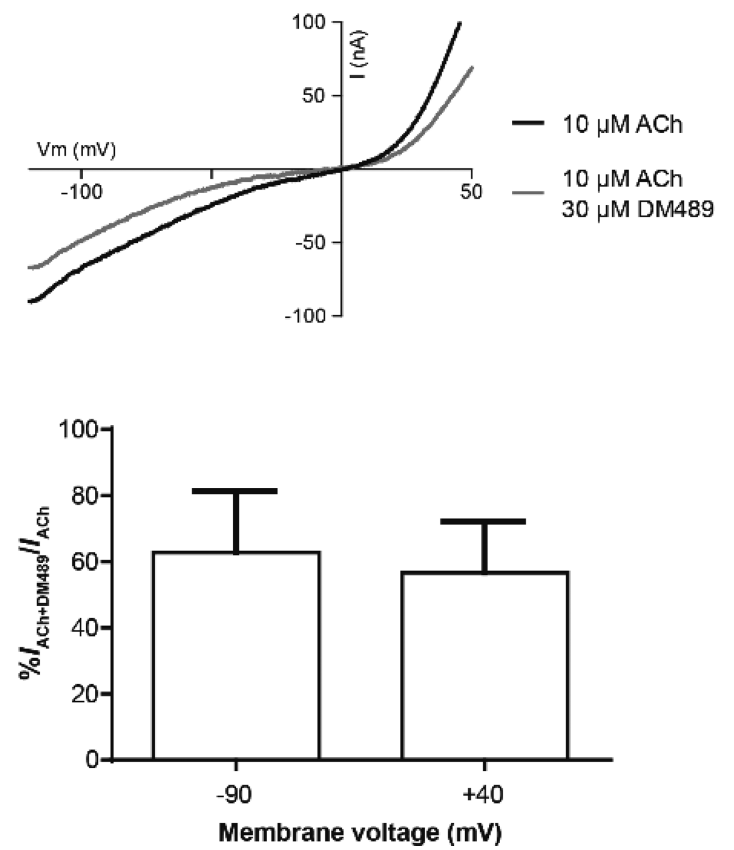

Figure 8. Effect of DM489 and PAM-2 on ACh-activated r $\alpha 9 \alpha 10$ nAChRs expressed in Xenopus oocytes. (A) Peak current amplitude of $\alpha 9 \alpha 10$ nAChRs elicited by $10 \mu \mathrm{M}$ ACh is diminished by either DM489 or PAM-2 in a concentration-dependent manner. (B) Concentration-response curves (mean \pm SEM; $n=3-6$ ) for the inhibitory activity of DM489 ( $\square$ ) and PAM-2 ( $\square$ ). Response was normalized to that elicited by $10 \mu$ M ACh (control set as $100 \%)$. The $\mathrm{IC}_{50}$ and $n_{\mathrm{H}}$ values were obtained by nonlinear least-squares fit and summarized in Table 2. (C) Current-voltage relationship for DM489 was obtained by applying $2 \mathrm{~s}$ voltage ramps from -120 to $+50 \mathrm{mV}, 10 \mathrm{~s}$ after the peak response to $10 \mu \mathrm{M}$ ACh from a holding potential $\left(V_{\text {hold }}\right)$ of $-70 \mathrm{mV}$, in the absence (black line) and presence (gray line) of $30 \mu \mathrm{M} \mathrm{DM} 489$. Paired Student's $t$ test analysis showed that DM489's inhibition is not significantly different $(P=0.38)$ between $-90 \mathrm{mV}(63 \pm 8 \%, n=6)$ and $+40 \mathrm{mV}(57 \pm 6 \%, n=6)$. 
A

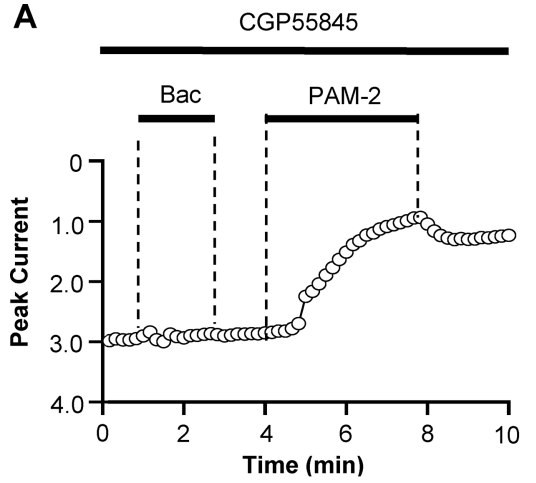

B

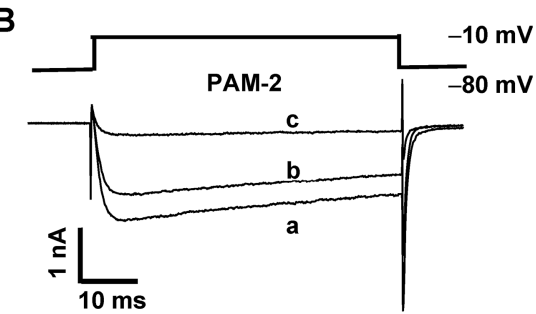

C

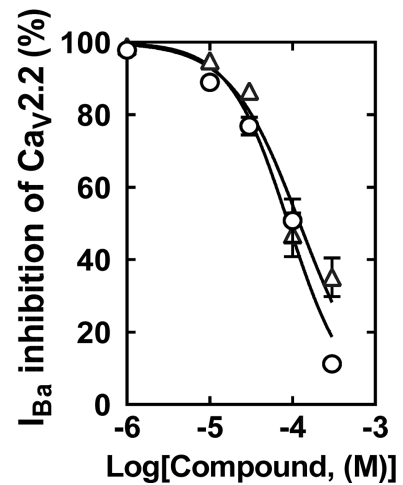

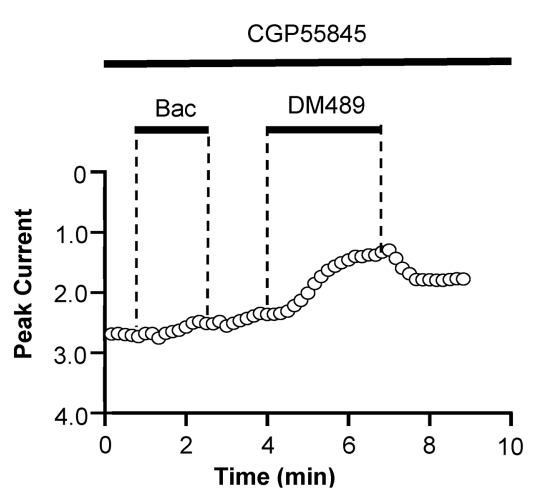

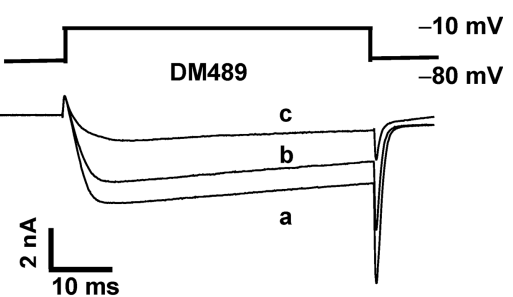
dependent plot of peak $\mathrm{Ba}^{2+}$ current $\left(I_{\mathrm{Ba}}\right)$ amplitudes before, during, and upon washout of $50 \mu \mathrm{M}( \pm)$-baclofen $(\mathrm{Bac}), 100 \mu \mathrm{M}$ PAM-2, and 100 $\mu \mathrm{M}$ DM489, in the continuous presence of the selective $\mathrm{GABA}_{\mathrm{B}} \mathrm{R}$ antagonist, CGP55845 (1 $\left.\mu \mathrm{M}\right)$. (B) Representative depolarization-activated $I_{\mathrm{Ba}}$ elicited from a holding potential of $-80 \mathrm{mV}$ to a test potential of $-10 \mathrm{mV}(50 \mathrm{~ms}$ duration; $0.1 \mathrm{~Hz})$ from HEK293T cells expressing Cav2.2 channels in the (a) absence and presence of (b) 30 and (c) $300 \mu \mathrm{M}$ PAM-2 or DM489. (C) Concentration-response relationship for PAM-2 (O) and DM489 $(\Delta)$ inhibition of hCa 2.2 channels expressed alone in HEK293T cells (mean \pm SEM; $n=4)$. The calculated $\mathrm{IC}_{50}$ and $n_{\mathrm{H}}$ values are summarized in Table 2.

prevented receptor dysregulation and upregulated $\alpha 7 \mathrm{nAChRs}$ in peripheral nerves and spinal cord as well as increased the density of glial cells in spinal cord and brain areas of näve rats. ${ }^{8}$ In conclusion, the PAM-induced $\alpha 7 \mathrm{nAChR}$ potentiation observed in our experiments could beneficially affect glial signaling, leading to pain control along with a significant neuroprotective effect. Since the repeated administration of $\alpha 7$-PAMs does not change the levels of $\alpha 7 \mathrm{nAChRs}$ in the brain, ${ }^{29}$ a mechanism involving PAM-induced up-regulation as part of the anti-neuropathic pain effects elicited by PAM-2 and DM489 can be ruled out. Considering that PAM-2 delays receptor desensitization, ${ }^{30}$ corresponding to the definition of type II PAMs, the possibility that $\alpha 7 \mathrm{nAChR}$ desensitization accounts for the anti-neuropathic pain effect of PAM-2 can also be dismissed.

\section{CONCLUSIONS}

The main objective of this study was to determine whether PAM-2 and its structural derivative DM489 have antineuropathic pain activity in mice by using the STZ- and oxaliplatin-induced neuropathic pain models. To define the mechanisms of action of these compounds, their pharmacological activities were determined at $\alpha 7$ and $\alpha 9 \alpha 10$ nAChRs, as well as $\mathrm{Ca}_{\mathrm{V}} 2.2$ channels alone or coupled with $\mathrm{GABA}_{\mathrm{B}} \mathrm{Rs}$ by electrophysiological recordings. This study clearly demonstrates that PAM-2 and DM489 reduce drug-induced neuropathic pain in mice and that $\alpha 7 \mathrm{nAChR}$ potentiation is likely the predominant molecular mechanism underlying this activity. Our results also suggest that PAM-2 and DM489 might be used for the prevention and treatment of chronic neuropathic pain, especially in chemotherapy and diabetes conditions. 


\section{METHODS}

Chemicals. Acetylcholine chloride (ACh), ( \pm )-baclofen, ethyl 3aminobenzoate methanesulfonate and BAPTA-AM were obtained from Sigma-Aldrich (St. Louis, MO), Streptozotocin (STZ), glucose, carboxymethyl cellulose, (E)-3-(furan-2-yl)acrylic acid, 1-hydroxybenzotriazole hydrate (HOBT), p-toluidine, indoline, and methyllycaconitine citrate (MLA) were obtained from Sigma-Aldrich SRL (Milan, Italy). Oxaliplatin was obtained from Carbosynth (Berkshire, UK). CGP55845 hydrochloride was purchased from Tocris Bioscience (Bristol, UK). HAM's F10 medium, horse serum, and hygromycin B were purchased from Thermo Fisher Scientific (Waltham, MA). Fetal bovine serum (FBS) was obtained from Bovogen (East Keilor, VIC, Australia) and Thermo Fisher Scientific. DMEM, GlutaMAX, penicillin, and streptomycin were purchased from Invitrogen Life Technologies (Carlsbad, CA). $N$-(3-Dimethylaminopropyl)- $N^{\prime}$-ethylcarbodiimide hydrochloride was obtained from Fluorochem (Glossop, UK). Salts and other compounds were of analytical grade.

Synthesis of PAM-2 and Its Novel Derivative DM489. For the synthesis of PAM-2 and DM489, a modification of the method described previously was used. ${ }^{15}$ (E)-3-(Furan-2-yl)acrylic acid (1.0 $\mathrm{mmol}$ ) was dissolved in anhydrous dichloromethane $(5 \mathrm{~mL})$, and the solution was cooled to $0{ }^{\circ} \mathrm{C}$. Then, triethylamine $(2.0 \mathrm{mmol})$ and the proper amine ( $p$-toluidine for PAM-2 or indoline for DM489, 1.0 mmol) was added (see Scheme 1 ). The mixture was maintained at 0 ${ }^{\circ} \mathrm{C}$ and stirred for $1 \mathrm{~h}$. Then, 1-hydroxybenzotriazole hydrate (HOBt) (2.0 mmol) and $\mathrm{N}$-(3-dimethylaminopropyl)- $\mathrm{N}^{\prime}$-ethylcarbodiimide hydrochloride (EDC $\mathrm{HCl})(2.0 \mathrm{mmol})$ were sequentially added, and the mixture was warmed to room temperature (RT) and stirred for 18 h. The mixture was next treated with dichloromethane $(15 \mathrm{~mL})$, and the organic layer was washed twice with $6 \mathrm{~N} \mathrm{HCl}(5 \mathrm{~mL})$. After drying with sodium sulfate, the solvent was removed under reduced pressure, and the residue was purified by flash silica gel chromatography [dichloromethane (99.9)/methanol (0.1), v:v], giving each purified compound.

Chemical Characterization. The uncorrected melting point of each compound was measured using a SMP3 apparatus (StuartBioCote, Staffordshire, UK). ${ }^{1} \mathrm{H}$ NMR and ${ }^{13} \mathrm{C}$ NMR spectra were recorded using a Bruker NMR 400 AVANCE spectrophotometer (Faellanden, Switzerland). Samples were dissolved in $\mathrm{CDCl}_{3}$ and placed in $5 \mathrm{~mm}$ NMR tubes. Measurements were taken using a $\mathrm{CDCl}_{3}$ lock and tetramethylsilane as the internal reference. ESI-MS spectra were obtained using a Varian $1200 \mathrm{~L}$ triple quadrupole system (Palo Alto, CA), equipped with an electrospray ionization source (ESI). Chromatographic separations were performed on a silica gel column (40, $0.040-0.063 \mathrm{~mm}$; Merck, Darmstadt, Germany) by flash chromatography. Compounds were named following IUPAC rules as applied by ChemBioDraw (version 14.0.0.117) software by PerkinElmer (Waltham, MA).

PAM-2 [(E)-3-(Furan-2-yl)-N-(p-tolyl)acrylamide] (Figure 1). ${ }^{1} \mathrm{H}$ NMR $\left(\mathrm{CDCl}_{3}, 400 \mathrm{MHz}\right): \delta 2.30\left(\mathrm{~s}, 3 \mathrm{H}, \mathrm{CH}_{3}\right), 6.43$ (dd, $J=3.3,1.8$ $\mathrm{Hz}, 1 \mathrm{H}), 6.50(\mathrm{~d}, J=19.1 \mathrm{~Hz}, 1 \mathrm{H}), 6.51(\mathrm{~s}, 1 \mathrm{H}), 7.10(\mathrm{~d}, J=8.2 \mathrm{~Hz}$, $2 \mathrm{H}), 7.40(\mathrm{~d}, J=1.3 \mathrm{~Hz}, 1 \mathrm{H}), 7.47-7.51(\mathrm{~m}, 3 \mathrm{H}), 7.73(\mathrm{bs}, 1 \mathrm{H}, \mathrm{NH})$ ppm. ${ }^{13} \mathrm{C}$ NMR $\left(\mathrm{CDCl}_{3}, 400 \mathrm{MHz}\right): \delta 20.9,112.2,114.2,118.7$, $120.0,128.7,129.5,144.2,151.3,164.0 \mathrm{ppm}$. ESI-LC/MS $\left(\mathrm{C}_{14} \mathrm{H}_{13} \mathrm{NO}_{2}\right): m / z 228.0[\mathrm{M}+\mathrm{H}]^{+}$; mp 161-162 ${ }^{\circ} \mathrm{C}$; yield $76.6 \%$. DM489 [(E)-3-(Furan-2-yl)-1-(indolin-1-yl)prop-2-en-1-one] (Figure 1). ${ }^{1} \mathrm{H}$ NMR $\left(\mathrm{CDCl}_{3}, 400 \mathrm{MHz}\right): \delta 3.15-3.21(\mathrm{~m}, 2 \mathrm{H}), 4.21(\mathrm{t}, J$ $=8.3 \mathrm{~Hz}, 2 \mathrm{H}), 6.46(\mathrm{dd}, J=3.3,1.8 \mathrm{~Hz}, 1 \mathrm{H}), 6.58(\mathrm{~d}, J=3.3 \mathrm{~Hz}$, $1 \mathrm{H}), 6.71-6.77(\mathrm{~m}, 1 \mathrm{H}), 7.00(\mathrm{t}, J=7.4 \mathrm{~Hz}, 1 \mathrm{H}), 7.16-7.25(\mathrm{~m}$, 2H), $7.46(\mathrm{~d}, J=1.0 \mathrm{~Hz}, 1 \mathrm{H}), 7.56(\mathrm{~d}, J=15.1 \mathrm{~Hz}, 1 \mathrm{H}), 8.32$ (bs, $1 \mathrm{H}) \mathrm{ppm} .{ }^{13} \mathrm{C} \mathrm{NMR}\left(\mathrm{CDCl}_{3}, 400 \mathrm{MHz}\right): \delta 27.9,48.1,112.3,114.5$, $116.6,117.4,123.8,124.5,127.5,129.6,144.2,151.6,164.1$ ppm. ESILC/MS $\left(\mathrm{C}_{15} \mathrm{H}_{13} \mathrm{NO}_{2}\right): m / z 240.1[\mathrm{M}+\mathrm{H}]^{+}$; mp 113-114 ${ }^{\circ} \mathrm{C}$; yield $87.3 \%$.

Lipophilicity and Brain Permeability Properties of PAM-2 and DM489. To predict whether PAM-2 and DM489 cross the blood-brain barrier, the lipophilicity (i.e., $\log \mathrm{P}$ ) and brain permeability $(\log B B=\log [$ brain $] /[$ plasma $])$ parameters were calculated using Biovia Discovery Studio software (Dassault Systèmes
Co., Waltham, MA). The scale for $\log B B$ ranges from values $\geq 0.7$ (very high brain penetration), $0.0-0.7$ (high penetration), and $<0.0$ to -0.52 (medium penetration) to $\leq-0.52$ (low penetration). The use of this software to estimate drug $\log B B$ values has been validated by the observed correlation between calculated and experimental values. ${ }^{31}$

Animals. Male CD-1 albino mice (Envigo, Varese, Italy), 2-3 months old (22-25 g), were used. Animals were housed in CeSAL (Centro Stabulazione Animali da Laboratorio, University of Florence) and used at least 1 week after their arrival. Ten mice were housed per cage $\left(\right.$ size $26 \times 41 \mathrm{~cm}^{2}$ ); animals were fed a standard laboratory diet and tap water ad libitum and kept at $23 \pm 1{ }^{\circ} \mathrm{C}$ with a $12 \mathrm{~h} \mathrm{light/dark}$ cycle, with light at $7 \mathrm{am}$. All animal manipulations were carried out according to the Directive 2010/63/EU of the European parliament and of the European Union council (September 22, 2010) on the protection of animals used for scientific purposes. Formal approval to conduct animal experiments was obtained from the Animal Subjects Review Board of the University of Florence, in compliance with the Guide for the Care and Use of Laboratory Animals of the NIH (USA). All efforts were made to minimize animal suffering and to reduce the number of animals used. A randomization of animals between groups and treatments was carried out. The investigators responsible for data analysis were blind to which animals represented treatments and controls.

Female X. laevis were sourced from Nasco (Fort Atkinson, WI), and a maximum of three frogs were kept in purpose-built $15 \mathrm{~L}$ aquarium at $20-26{ }^{\circ} \mathrm{C}$ with a $12 \mathrm{~h}$ light/dark cycle. Oocytes were obtained from three frogs (five years old) anaesthetized with $1.7 \mathrm{mg} /$ $\mathrm{mL}$ ethyl 3-aminobenzoate methanesulfonate ( $\mathrm{pH} 7.4$ with $\mathrm{NaHCO}_{3}$ ), and for recovery, post-surgery animals were placed in fresh water at a level below the nostrils. Frogs were allowed to recover for a minimum of four months between surgeries. Terminal anesthesia with $5 \mathrm{mg} / \mathrm{mL}$ ethyl 3 -aminobenzoate methanesulfonate $(\mathrm{pH} 7.4$ with $\mathrm{NaHCO}_{3}$ ) was performed on frogs at the sixth surgery. All procedures were approved by the Animal Ethics Committees from University of Wollongong, University of Sydney, and Universidad de Buenos Aires.

Treatment of PAM-2 and DM489 on StreptozotocinInduced Neuropathic Pain. To develop neuropathic pain, mice ( $n=10 /$ condition) were treated with a single intraperitoneal (ip) injection of $100 \mathrm{mg} / \mathrm{kg}$ streptozotocin (STZ) [dissolved in $0.1 \mathrm{M}$ citrate buffer, $\mathrm{pH} 4.5$ (vehicle)] on day 1 after overnight fasting as described previously. ${ }^{17,18}$ The solution of STZ was prepared immediately before the injection. Control animals received an equivalent volume of vehicle. Three days later, glycemia was measured by blood sampling from the caudal vein and analyzed with the AccuCheck Aviva planar sensor (glucose oxidase method; Roche, Italy). STZ-treated animals with blood glucose levels $<270 \mathrm{mg} / \mathrm{dL}$ were rejected from the study. Animals were then group-housed with full access to food and water for 2 weeks. To maintain cleanliness and avoid the development of any infection due to excessive urination, animal bedding was frequently changed. On day 15 , the pain threshold was evaluated by the cold plate test at $0,15,30,45$, and 60 min, revealing significant hypersensitivity of STZ-treated animals. Mice were then per os (p.o.) administrated with PAM-2 (1 and $3 \mathrm{mg}$ / $\mathrm{kg}$ ) or DM489 (3 and $10 \mathrm{mg} / \mathrm{kg}$ ) [each suspended in $1 \%$ carboxymethylcellulose (i.e., vehicle)], and the anti-nociceptive activity of these compounds was subsequently evaluated by the cold plate test.

Treatment of PAM-2 and DM489 on Oxaliplatin-Induced Neuropathic Pain. To develop neuropathic pain, mice $(n=10 /$ condition) were administered (ip) with $2.4 \mathrm{mg} / \mathrm{kgoxaliplatin}$ [dissolved in $5 \%$ glucose solution (vehicle)] on days 1-3, 6-10, and $13-14 .{ }^{3,5}$ Control animals received an equivalent volume of vehicle. On day 15 , the pain threshold was evaluated by the cold plate test at $0,15,30,45$, and $60 \mathrm{~min}$, revealing significant hypersensitivity of oxaliplatin-treated animals. Mice were then administrated (p.o.) with PAM-2 (1 and $3 \mathrm{mg} / \mathrm{kg}$ ) or DM489 (10 and $30 \mathrm{mg} / \mathrm{kg}$ ) [each suspended in $1 \%$ carboxymethyl cellulose (i.e., vehicle)], and the pain threshold was subsequently determined by the cold plate test. 
Coadministration of PAM-2 and Oxaliplatin. To determine whether PAM-2 decreases the development of neuropathic pain induced by oxaliplatin, mice $(n=10 /$ condition) were coadministered with $2.4 \mathrm{mg} / \mathrm{kg}$ oxaliplatin and an inactive dose of PAM-2 $(1 \mathrm{mg} / \mathrm{kg}$; p.o.) following the same protocol as that for oxaliplatin alone. Pain threshold values corresponding to 7 and 14 days of cotreatment were determined $24 \mathrm{~h}$ after the last administration by using the cold plate test. To determine whether an additional administration of PAM-2 increases its efficacy, animals were administered with $1 \mathrm{mg} / \mathrm{kg}$ PAM-2 after $30 \mathrm{~min}$ of the last cotreatment/cold plate test, and the pain threshold was subsequently assessed.

Effect of Methyllycaconitine on the Anti-Neuropathic Pain Activity Mediated by PAM-2 and DM489. To determine whether the anti-neuropathic pain activity elicited by $3 \mathrm{mg} / \mathrm{kg}$ PAM- 2 or 30 $\mathrm{mg} / \mathrm{kg}$ DM489 is mediated by $\alpha 7 \mathrm{nAChRs}$, mice $(n=10 /$ condition $)$ were administered (ip) with $6 \mathrm{mg} / \mathrm{kg}$ methyllycaconitine (MLA), an $\alpha 7$-selective antagonist, ${ }^{24} 15 \mathrm{~min}$ before the tested drug or vehicle. Pain threshold measurements were performed at 15, 30, 45, and 60 min after treatment by using the cold plate test.

Cold Plate Test. The animals were placed in a stainless steel box $(12 \mathrm{~cm} \times 20 \mathrm{~cm} \times 10 \mathrm{~cm})$ with a cold plate as the floor. The temperature of the cold plate was kept constant at $4 \pm 1{ }^{\circ} \mathrm{C}$. Painrelated behavior (licking of the hind paw) was observed, and the time (s) of the first sign was subsequently recorded (i.e., licking latency). The cutoff time of the latency of paw lifting or licking was set at $60 \mathrm{~s} .5$

Comparative Activity of PAM-2 and DM489 at Human and Rat $\alpha 7$ nAChRs Heterologously Expressed in Xenopus laevis Oocytes. Stage V-VI oocytes (Dumont's classification; 1200-1300 $\mu \mathrm{m}$ in diameter) were obtained from X. laevis, defolliculated with 1.5 $\mathrm{mg} / \mathrm{mL}$ collagenase Type II at RT $\left(21-24{ }^{\circ} \mathrm{C}\right)$ for $1-2 \mathrm{~h}$ in OR-2 solution containing (in $\mathrm{mM}) 82.5 \mathrm{NaCl}, 2 \mathrm{KCl}, 1 \mathrm{MgCl}_{2}$, and 5 HEPES, at $\mathrm{pH}$ 7.4. Oocytes were injected with $10 \mathrm{ng}$ of either human (h) $\alpha 7$ or rat (r) $\alpha 7$ cRNAs (concentration confirmed spectrophotometrically and by gel electrophoresis) using glass pipettes (3-000-203 GX, Drummond Scientific Co., Broomall, PA). For the synthesis of $\alpha 7$ nAChR subunit cRNAs, plasmid pMXT construct of $h \alpha 7$ and plasmid pNKS2 construct of $\mathrm{r} \alpha 7$ were linearized with BamHI (NEB, Ipswich, $\mathrm{MA}$ ) and $\mathrm{XbaI}$ (NEB), respectively, for in vitro SP6 mMessage mMachine-cRNA transcription (AMBION, Foster City, CA). Both $\alpha 7$ nAChR constructs were sourced from Prof. J. Lindstrom (University of Pennsylvania, Philadelphia, PA).

Oocytes were incubated at $18{ }^{\circ} \mathrm{C}$ in sterile ND96 solution composed of (in $\mathrm{mM}$ ) $96 \mathrm{NaCl}, 2 \mathrm{KCl}, 1 \mathrm{CaCl}_{2}, 1 \mathrm{MgCl}_{2}$, and 5 HEPES, pH 7.4, supplemented with $5 \% \mathrm{FBS}, 0.1 \mathrm{mg} / \mathrm{mL}$ gentamicin, and $100 \mathrm{U} / \mathrm{mL}$ penicillin-streptomycin. Electrophysiological recordings were carried out 2-7 days post-cRNA microinjection. Twoelectrode voltage clamp recordings of $X$. laevis oocytes expressing $\alpha 7$ nAChRs were performed at room temperature (RT) using a GeneClamp 500B amplifier and pClamp9 software interface (Molecular Devices, San Jose, CA) at a holding potential of -80 $\mathrm{mV}$. Voltage-recording and current-injecting electrodes were pulled from GC150T-7.5 borosilicate glass (Harvard Apparatus, Holliston, $\mathrm{MA}$ ) and filled with $3 \mathrm{M} \mathrm{KCl}$, giving resistances of $0.3-1 \mathrm{M} \Omega$.

Oocytes expressing $\alpha 7 \mathrm{nAChRs}$ were perfused with ND96 solution at a rate of $2 \mathrm{~mL} / \mathrm{min}$. Initially, oocytes were briefly washed with ND96 solution followed by three applications of ACh at concentrations corresponding to the $20 \%$ maximal effective concentration (i.e., $\left.\mathrm{EC}_{20}\right)$ for $\mathrm{h} \alpha 7(30 \mu \mathrm{M})$ and $\mathrm{r} \alpha 7(160 \mu \mathrm{M})$ nAChRs (Figure 7B), respectively, and 3 min washout between ACh applications. The $\mathrm{ACh} \mathrm{EC}_{20}$ value used for $\mathrm{h} \alpha 7$ was calculated from

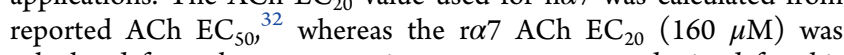
calculated from the concentration-response curve obtained for this subtype (see Figure 7B).

Peak current amplitudes before and after incubation were measured using Clampfit 10.7 software (Molecular Devices), and the relative current amplitude, $I_{\mathrm{ACh}+\text { compound }} / I_{\mathrm{ACh}}(\Lambda)$, was used to assess the compound's activity at $\mathrm{nAChRs}$. Solutions containing the compound were prepared in ND96 + 0.1\% FBS. Oocytes were incubated with PAM-2 or DM489 for 5 min with the perfusion system stopped, followed by coapplication of ACh plus the compound with flowing bath solution. Incubation with $0.1 \%$ FBS was performed to ensure that the FBS and the pressure of the perfusion system had no effect on nAChRs.

Voltage Clamp Recordings of Oocytes Expressing $r \alpha 9 \alpha 10$ nAChRs. For the expression studies, $\mathrm{r} \alpha 9$ and $\mathrm{r} \alpha 10$ subunits were subcloned into a modified pGEMHE vector. Capped cRNAs were in vitro transcribed from linearized plasmid DNA templates using RiboMAX Large Scale RNA Production System (Promega, Madison, WI). The maintenance of $X$. laevis and the preparation and cRNA injection of stages V and VI oocytes have been described in detail elsewhere. ${ }^{33}$ Typically, oocytes were injected with $50 \mathrm{~nL}$ of RNasefree water containing 0.01-1.0 ng of cRNA (at a 1:1 molar ratio when pairwise combined) and maintained in Barth's solution at $18{ }^{\circ} \mathrm{C}$. Electrophysiological recordings were performed 2-6 days after cRNA injection under two-electrode voltage clamp with an Oocyte Clamp OC-725B or C amplifier (Warner Instruments Corp., Hamden, CT). Recordings were filtered at a cutoff frequency of $10 \mathrm{~Hz}$ using a 900BT Tunable Active Filter (Frequency Devices Inc., Ottawa, IL). Data acquisition was performed using a Patch Panel PP-50 LAB/1 interphase (Warner Instruments Corp., Hamden, CT) at a rate of 10 points/s. Both voltage and current electrodes were filled with $3 \mathrm{M}$ $\mathrm{KCl}$ and had resistances of $\sim 1 \mathrm{M} \Omega$. Data were analyzed using Clampfit from the pClamp 6.1 software. During electrophysiological recordings, oocytes were continuously superfused $(\sim 15 \mathrm{~mL} / \mathrm{min})$ with normal frog saline containing (in $\mathrm{mM}$ ) $115 \mathrm{NaCl}, 2.5 \mathrm{KCl}, 1.8$ $\mathrm{CaCl}_{2}$, and 10 HEPES, pH 7.2. ACh and PAM-2 or DM489 were added to the perfusion solution. Unless otherwise indicated, the membrane potential was held at $-70 \mathrm{mV}$. To minimize endogenous $\mathrm{Ca}^{2+}$-dependent chloride currents, oocytes were incubated with the $\mathrm{Ca}^{2+}$ chelator BAPTA-AM $(100 \mu \mathrm{M})$ for $3 \mathrm{~h}$ before electrophysiological recordings. PAM-2 and DM489 concentration-inhibition curves were performed on ACh-activated $\alpha 9 \alpha 10 \mathrm{nAChRs,} \mathrm{using}$ a concentration of $\mathrm{ACh}$ (i.e., $10 \mu \mathrm{M}$ ) corresponding to its $\mathrm{EC}_{50}$ value. Oocytes were preincubated for 2 min with the compound under study before adding $\mathrm{ACh}+$ compound.

Current-voltage $(I-V)$ relationships in the absence and presence of $30 \mu \mathrm{M}$ DM489 were obtained by applying $2 \mathrm{~s}$ voltage ramps from -120 to $+50 \mathrm{mV}, 10 \mathrm{~s}$ after the peak response to $10 \mu \mathrm{M} \mathrm{ACh}$ from a holding potential $\left(V_{\text {hold }}\right)$ of $-70 \mathrm{mV}$. Leakage correction was performed by subtraction of the $I-V$ curve obtained by the same voltage ramp protocol before the application of ACh. Data were analyzed using Clampfit from the pClamp 6.1 software.

Whole-Cell Patch Clamp Recording of HEK293T Cells Expressing $\mathrm{Ca}_{\mathrm{v}} 2.2$ Channels Alone or Coexpressing $\mathrm{GABA}_{\mathrm{B}} \mathrm{Rs}$. HEK293T cells (ATCC, Manassas, VA) were cultured in DMEM supplemented with $10 \% \mathrm{FBS}, 1 \%$ penicillin and streptomycin, and $1 \times$ GlutaMAX at $37{ }^{\circ} \mathrm{C}$ in $5 \% \mathrm{CO}_{2}$. Cells were plated on $12 \mathrm{~mm}$ glass coverslips and transiently transfected using the calcium phosphate method. The tricistronic plasmid cDNA3.1 construct containing human $\mathrm{GABA}_{\mathrm{B}} \mathrm{R} 1$ and $\mathrm{GABA}_{\mathrm{B}} \mathrm{R} 2$ subunits, and the green fluorescent protein (GFP), was cotransfected with plasmid cDNA3.1 constructs encoding hCa $2.2 \alpha 1 \mathrm{~B}, \alpha 2 \delta 1$, and $\beta 3$ subunits (all constructs were inhouse generated) at $2 \mu \mathrm{g}$ each. The plasmid construct of GFP ( 0.5 $\mu \mathrm{g})$ was only cotransfected with pCDNA3.1 constructs of $\mathrm{Ca}_{\mathrm{V}} 2.2$ $\alpha 1 \mathrm{~B}, \alpha 2 \delta 1$, and $\beta 3$ subunits for the identification of transfected cells.

Whole-cell patch clamp recordings were performed within $24-48 \mathrm{~h}$ post-transfection at RT $\left(21-23{ }^{\circ} \mathrm{C}\right)$. Cells were constantly superfused using a gravity flow perfusion system (AutoMate Scientific, Berkeley, CA) with extracellular solution containing (in $\mathrm{mM}$ ) $110 \mathrm{NaCl}, 10$ $\mathrm{BaCl}_{2}, 1 \mathrm{MgCl}_{2}, 5 \mathrm{CsCl}, 30$ TEA-Cl, 10 glucose, and $10 \mathrm{HEPES}(\mathrm{pH}$ 7.35 with TEA-OH; $\sim 310 \mathrm{mOsmol} / \mathrm{kg}$ ). Fire-polished borosilicate patch pipettes (2-3 M $\Omega$ ) were filled with intracellular solution containing (in $\mathrm{mM}$ ) $125 \mathrm{~K}$-gluconate, $5 \mathrm{NaCl}, 2 \mathrm{MgCl}_{2}, 5 \mathrm{EGTA}$, and 10 HEPES (pH 7.2 with $\mathrm{KOH} ; 290 \mathrm{mOsmol} / \mathrm{kg}$ ). Inward $\mathrm{Ba}^{2+}$ currents were elicited by a test depolarization to $-10 \mathrm{mV}(50 \mathrm{~ms}$ duration) from a holding potential of $-80 \mathrm{mV}$ applied at $0.1 \mathrm{~Hz}$. Solutions containing PAM-2 or DM489 were prepared in the external solution.

Statistical Analysis of Data. The concentration-response relationship for PAM-2 and DM489 was analyzed using the Prism 7 
software (GraphPad, La Jolla, CA) according to one- and twocomponent (see eq 1) Hill equation:

$$
\begin{aligned}
I_{\text {comp }}= & 100+\Delta E_{\max } \times[\text { comp }]^{n_{\mathrm{H}}} /\left([\mathrm{comp}]^{n_{\mathrm{H}}}+\mathrm{EC}_{50}{ }^{{ }}{ }_{\mathrm{H}}\right) \\
& +\left(I_{\text {sat }}-\Delta E_{\text {max }}\right) \times[\mathrm{comp}]^{n_{\mathrm{H}}} /\left([\mathrm{comp}]^{n_{\mathrm{H}}}+\mathrm{IC}_{50}{ }^{{ } \mathrm{H}}\right)
\end{aligned}
$$

where $I_{\text {comp }}$ is the current in the presence of the compound (expressed as\% of control current), $\Delta E_{\max }$ is the maximal potentiating effect (compound efficacy; considering control $100 \%), I_{\text {sat }}$ is the current at saturating compound concentration (expressed as\% control), [comp] is the compound concentration, $n_{\mathrm{H}}$ is the Hill coefficient, $\mathrm{EC}_{50}$ is the compound concentration to produce $50 \%$ potentiation, and $\mathrm{IC}_{50}$ is the compound concentration to produce $50 \%$ inhibition.

The inhibition of $r \alpha 9 \alpha 10 \mathrm{nAChRs}$ determined at different voltage values was compared by paired Student's $t$ test. Values of $P<0.05$ were considered statistically significant. One-way ANOVA analyses and the subsequent Bonferroni post hoc comparison of the behavioral data were assessed by using the Origin 9 software (OriginLab Corp., Northampton, MA). Values of $P<0.05$ were considered statistically significant.

\section{AUTHOR INFORMATION}

\section{Corresponding Authors}

Hugo R. Arias - Department of Pharmacology and Physiology, College of Osteopathic Medicine, Oklahoma State University Center for Health Sciences, Tahlequah, Oklahoma 74464, United States; Phone: (918) 525-6324; Email: hugo.arias@ okstate.edu; Fax: (918) 280-1847

Han-Shen Tae - Illawarra Health and Medical Research Institute (IHMRI), University of Wollongong, Wollongong, NSW 2522, Australia; 이이이.0rg/0000-0001-8961-7194; Phone: (61) 24221 5426; Email: hstae@uow.edu.au; Fax: (61) 242218130

\section{Authors}

Carla Ghelardini - Department of Neurosciences, Psychology, Drug Research and Child Health (NEUROFARBA) and, Section of Pharmacology and Toxicology, University of Florence, Florence 50019, Italy

Elena Lucarini - Department of Neurosciences, Psychology, Drug Research and Child Health (NEUROFARBA) and, Section of Pharmacology and Toxicology, University of Florence, Florence 50019, Italy

Arsalan Yousuf - Illawarra Health and Medical Research Institute (IHMRI), University of Wollongong, Wollongong, NSW 2522, Australia

Irina Marcovich - Instituto de Investigaciones en Ingenieria Genética y Biologia Molecular "Dr. Hector N. Torres", (INGEBI), Consejo Nacional de Investigaciones Cientificas y Téchnicas (CONICET), Universidad de Buenos Aires, Bueno Aires C1121, Argentina

Dina Manetti - Section of Pharmaceutical and Nutraceutical Sciences, University of Florence, Florence 50019, Italy; (ㄱ) orcid.org/0000-0002-5881-6550

Maria Novella Romanelli - Section of Pharmaceutical and Nutraceutical Sciences, University of Florence, Florence 50019, Italy; (i) orcid.org/0000-0002-5685-3403

Ana Belén Elgoyhẹn - Instituto de Investigaciones en Ingeniería Genética y Biologia Molecular "Dr. Hector N. Torres", (INGEBI), Consejo Nacional de Investigaciones Cientificas y Téchnicas (CONICET) and Instituto de Farmacologia, Facultad de Medicina, Universidad de Buenos Aires, Bueno Aires C1121, Argentina
David J. Adams - Illawarra Health and Medical Research Institute (IHMRI), University of Wollongong, Wollongong, NSW 2522, Australia; 이이이.org/0000-0002-7030-2288

Lorenzo Di Cesare Mannelli - Department of Neurosciences, Psychology, Drug Research and Child Health (NEUROFARBA) and, Section of Pharmacology and Toxicology, University of Florence, Florence 50019, Italy

Complete contact information is available at: https://pubs.acs.org/10.1021/acschemneuro.0c00476

\section{Author Contributions}

H.R.A. developed the concept and wrote the overall manuscript. D.M. and M.N.R. synthesized the compounds and wrote the synthesis method. E.L. performed the animal studies. H.S.T., I.M., and A.Y. performed the electrophysiological experiments. A.B.E. and D.J.A. supervised the electrophysiological experiments. H.R.A., E.L., H.-S.T., I.M., A.Y., C.G., and L.D.C.M. performed data analyses. H.-S.T., A.Y., and L.D.C.M. wrote the methods and results of the electrophysiological and animal studies, respectively. H.R.A., C.G., D.J.A., and L.D.C.M. contributed to critical comments on the manuscript and discussion.

\section{Funding}

This work was supported by grants from OVPR Pilot/Seed Grant (Oklahoma State University Center for Health Sciences) (to H.R.A.), Italian Ministry of Instruction, University and Research (MIUR), and University of Florence, Italy (to C.G.), National Agency for Scientific and Technologic Promotion, Argentina (to A.B.E.), and Australian Research Council (Discovery Project Grant DP150103990 to D.J.A.).

\section{Notes}

The authors declare no competing financial interest.

\section{ACKNOWLEDGMENTS}

The authors would like to thank Prof. J. Lindstrom for the $\alpha 7$ nAChR constructs and Dr. M. Ortells for the calculation of the $\operatorname{LogBB}$ values.

\section{ABBREVIATIONS}

$\mathrm{ACh}$, acetylcholine; $\mathrm{nAChR}$, nicotinic acetylcholine receptor; $\mathrm{GABA}_{\mathrm{B}} \mathrm{R}, \gamma$-aminobutyric acid type $\mathrm{B}$ receptor; $\mathrm{Ca}_{\mathrm{V}} 2.2$, voltage-gated $\mathrm{N}$-type calcium channel; STZ, streptozotocin; $\mathrm{RT}$, room temperature; PAM, positive allosteric modulator; NAM, negative allosteric modulator; PAM-2, (E)-3-furan-2-yl$\mathrm{N}$-p-tolyl-acrylamide; DM489, (E)-3-(furan-2-yl)-1-(indolin-1yl)prop-2-en-1-one; MLA, methyllycaconitine; $\mathrm{EC}_{50}$, ligand concentration that produces half-maximal potentiation; $\mathrm{EC}_{20}$, ligand concentration that produces $20 \%$ maximal potentiation; $\Delta E_{\max }$ maximal potentiation compared to control (100\%); $\mathrm{IC}_{50}$, ligand concentration that produces half-maximal inhibition; $n_{\mathrm{H}}$, Hill coefficient; FBS, fetal bovine serum

\section{REFERENCES}

(1) Arias, H. R. (2010) Positive and negative modulation of nicotinic receptors. In Advances in Protein Chemistry and Structural Biology (Donev, R., Ed.) Vol. 80, pp 153-203, Academic Press.

(2) Elgoyhen, A. B., Vetter, D. E., Katz, E., Rothlin, C. V., Heinemann, S. F., and Boulter, J. (2001) $\alpha 10$ : a determinant of nicotinic cholinergic receptor function in mammalian vestibular and cochlear mechanosensory hair cells. Proc. Natl. Acad. Sci. U. S. A. 98 (6), 3501-3506.

(3) Colomer, C., Olivos-Oré, L. A., Vincent, A., McIntosh, J. M., Artalejo, A. R., and Guérineau, N. C. (2010) Functional character- 
ization of $\alpha 9$-containing cholinergic nicotinic receptors in the rat adrenal medulla: implication in stress-induced functional plasticity. $J$. Neurosci. 30 (19), 6732-6742.

(4) Fujii, T., Mashimo, M., Moriwaki, Y., Misawa, H., Ono, S., Horiguchi, K., and Kawashima, K. (2017) Expression and function of the cholinergic system in immune cells. Front. Immunol. 8, 1085.

(5) Arias, H. R., Tae, H.-S., Micheli, L., Yousuf, A., Ghelardini, C., Adams, D. J., and Di Cesare Mannelli, L. (2020) Coronaridine congeners decrease neuropathic pain in mice and inhibit $\alpha 9 \alpha 10$ nicotinic acetylcholine receptors and $\mathrm{Ca}_{\mathrm{V}} 2.2$ channels. Neuropharmacology 175, 108194.

(6) Hone, A. J., and McIntosh, J. M. (2018) Nicotinic acetylcholine receptors in neuropathic and inflammatory pain. FEBS Lett. 592 (7), $1045-1062$.

(7) Atzori, M., Garcia-Oscos, F., and Arias, H. R. (2016) $\alpha 7$ nicotinic acetylcholine receptor-mediated anti-inflammatory actions modulate brain functions. Neurotransmitter 3, No. e1303.

(8) Di Cesare Mannelli, L., Pacini, A., Matera, C., Zanardelli, M., Mello, T., De Amici, M., Dallanoce, C., and Ghelardini, C. (2014) Involvement of $\alpha 7 \mathrm{nAChR}$ subtype in rat oxaliplatin-induced neuropathy: effects of selective activation. Neuropharmacology 79, 37-48.

(9) Haberberger, R. V., Bernardini, N., Kress, M., Hartmann, P., Lips, K. S., and Kummer, W. (2004) Nicotinic acetylcholine receptor subtypes in nociceptive dorsal root ganglion neurons of the adult rat. Auton. Neurosci. 113 (1-2), 32-42.

(10) Alsharari, S. D., Freitas, K., and Damaj, M. I. (2013) Functional role of $\alpha 7$ nicotinic receptor in chronic neuropathic and inflammatory pain: studies in transgenic mice. Biochem. Pharmacol. 86 (8), 12011207.

(11) Rowley, T. J., McKinstry, A., Greenidge, E., Smith, W., and Flood, P. (2010) Antinociceptive and anti-inflammatory effects of choline in a mouse model of postoperative pain. Br. J. Anaesth. 105 (2), 201-207.

(12) Gao, B., Hierl, M., Clarkin, K., Juan, T., Nguyen, H., Valk, M., Deng, H., Guo, W., Lehto, S. G., Matson, D., McDermott, J. S., Knop, J., Gaida, K., Cao, L., Waldon, D., Albrecht, B. K., Boezio, A. A., Copeland, K. W., Harmange, J. C., Springer, S. K., Malmberg, A. B., and McDonough, S. I. (2010) Pharmacological effects of nonselective and subtype-selective nicotinic acetylcholine receptor agonists in animal models of persistent pain. Pain 149 (1), 33-49.

(13) Bagdas, D., Gurun, M. S., Flood, P., Papke, R. L., and Damaj, M. I. (2018) New insights on neuronal nicotinic acetylcholine receptors as targets for pain and inflammation: a focus on $\alpha 7$ nAChRs. Curr. Neuropharmacol. 16 (4), 415-425.

(14) Freitas, K., Carroll, F. I., and Damaj, M. I. (2013) The antinociceptive effects of nicotinic receptors $\alpha 7$-positive allosteric modulators in murine acute and tonic pain models. J. Pharmacol. Exp. Ther. 344 (1), 264-275.

(15) Arias, H. R., Gu, R. X., Feuerbach, D., Guo, B. B., Ye, Y., and Wei, D. Q. (2011) Novel positive allosteric modulators of the human $\alpha 7$ nicotinic acetylcholine receptor. Biochemistry 50 (23), 5263-5278.

(16) Di Cesare Mannelli, L., Pacini, A., Bonaccini, L., Zanardelli, M., Mello, T., and Ghelardini, C. (2013) Morphologic features and glial activation in rat oxaliplatin-dependent neuropathic pain. J. Pain 14 (12), 1585-1600.

(17) Lucarini, E., Pagnotta, E., Micheli, L., Parisio, C., Testai, L., Martelli, A., Calderone, V., Matteo, R., Lazzeri, L., Di Cesare Mannelli, L., and Ghelardini, C. (2019) Eruca sativa meal against diabetic neuropathic pain: $\mathrm{An} \mathrm{H}_{2} \mathrm{~S}$-mediated effect of glucoerucin. Molecules 24 (16), 3006.

(18) O’Brien, P. D., Sakowski, S. A., and Feldman, E. L. (2014) Mouse models of diabetic neuropathy. ILAR J. 54 (3), 259-272.

(19) Adams, D. J., Callaghan, B., and Berecki, G. (2012) Analgesic conotoxins: block and $\mathrm{G}$ protein-coupled receptor modulation of $\mathrm{N}$ type $\left(\mathrm{Ca}_{\mathrm{V}} 2.2\right)$ calcium channels. Br. J. Pharmacol. 166 (2), 486-500.

(20) Zamponi, G. W., Striessnig, J., Koschak, A., and Dolphin, A. C. (2015) The physiology, pathology, and pharmacology of voltage- gated calcium channels and their future therapeutic potential. Pharmacol. Rev. 67 (4), 821-870.

(21) Potasiewicz, A., Holuj, M., Kos, T., Popik, P., Arias, H. R., and Nikiforuk, A. (2017) 3-Furan-2-yl-N-p-tolyl-acrylamide, a positive allosteric modulator of the $\alpha 7$ nicotinic receptor, reverses schizophrenia-like cognitive and social deficits in rats. Neuropharmacology 113 (Pt A), 188-197.

(22) Targowska-Duda, K. M., Budzynska, B., Michalak, A., Jozwiak, K., Biala, G., and Arias, H. R. (2019) 3-Furan-2-yl-N-p-tolylacrylamide, a highly selective positive allosteric modulator of $\alpha 7$ nicotinic receptors, produces anxiolytic-like activity in mice. $J$. Psychopharmacol. 33 (5), 558-567.

(23) Targowska-Duda, K. M., Feuerbach, D., Biala, G., Jozwiak, K., and Arias, H. R. (2014) Antidepressant activity in mice elicited by 3furan-2-yl-N-p-tolyl-acrylamide, a positive allosteric modulator of the $\alpha 7$ nicotinic acetylcholine receptor. Neurosci. Lett. 569, 126-130.

(24) Arias, H. R., Gu, R.-X., Feuerbach, D., and Wei, D.-Q. (2010) Different interaction between the agonist JN403 and the competitive antagonist methyllycaconitine with the human $\alpha 7$ nicotinic acetylcholine receptor. Biochemistry 49 (19), 4169-4180.

(25) Bagdas, D., Targowska-Duda, K. M., Lopez, J. J., Perez, E. G., Arias, H. R., and Damaj, M. I. (2015) The antinociceptive and antiinflammatory properties of 3-furan-2-yl-N-p-tolyl-acrylamide, a positive allosteric modulator of $\alpha 7$ nicotinic acetylcholine receptors in mice. Anesth. Analg. 121 (5), 1369-1377.

(26) Sadeghi, M., Carstens, B. B., Callaghan, B. P., Daniel, J. T., Tae, H.-S., O’Donnell, T., Castro, J., Brierley, S. M., Adams, D. J., Craik, D. J., and Clark, R. J. (2018) Structure-activity studies reveal the molecular basis for $\mathrm{GABA}_{\mathrm{B}}$ receptor mediated inhibition of high voltage-activated calcium channels by $\alpha$-conotoxin Vc1.1. ACS Chem. Biol. 13 (6), 1577-1587.

(27) Patel, R., Montagut-Bordas, C., and Dickenson, A. H. (2018) Calcium channel modulation as a target in chronic pain control. $\mathrm{Br}$. J. Pharmacol. 175 (12), 2173-2184.

(28) Parada, E., Egea, J., Buendia, I., Negredo, P., Cunha, A. C. Cardoso, S., Soares, M. P., and Lopez, M. G. (2013) The microglial $\alpha 7$-acetylcholine nicotinic receptor is a key element in promoting neuroprotection by inducing heme oxygenase-1 via nuclear factor erythroid-2-related factor 2. Antioxid. Redox Signaling 19 (11), 11351148.

(29) Christensen, D. Z., Mikkelsen, J. D., Hansen, H. H., and Thomsen, M. S. (2010) Repeated administration of $\alpha 7$ nicotinic acetylcholine receptor (nAChR) agonists, but not positive allosteric modulators, increases $\alpha 7 \mathrm{nAChR}$ levels in the brain. J. Neurochem. 114 (4), 1205-1216.

(30) Andersen, N. D., Nielsen, B. E., Corradi, J., Tolosa, M. F., Feuerbach, D., Arias, H. R., and Bouzat, C. (2016) Exploring the positive allosteric modulation of human $\alpha 7$ nicotinic receptors from a single-channel perspective. Neuropharmacology 107, 189-200.

(31) Yang, T., Zang, D.-W., Shan, W., Guo, A.-C., Wu, J.-P., Wang, Y.-J., and Wang, Q. (2019) Synthesis and evaluations of novel apocynin derivatives as anti-glioma agents. Front. Pharmacol. 10, 951.

(32) Thomsen, M. S., Zwart, R., Ursu, D., Jensen, M. M., Pinborg, L. H., Gilmour, G., Wu, J., Sher, E., and Mikkelsen, J. D. (2015) $\alpha 7$ and $\beta 2$ nicotinic acetylcholine receptor subunits form heteromeric receptor complexes that are expressed in the human cortex and display distinct pharmacological properties. PLoS One 10 (6), No. e0130572.

(33) Ballestero, J. A., Plazas, P. V., Kracun, S., Gomez-Casati, M. E., Taranda, J., Rothlin, C. V., Katz, E., Millar, N. S., and Elgoyhen, A. B. (2005) Effects of quinine, quinidine, and chloroquine on $\alpha 9 \alpha 10$ nicotinic cholinergic receptors. Mol. Pharmacol. 68 (3), 822-829. 